\title{
Sequence-dependent effect of sorafenib in combination with natural phenolic compounds on hepatic cancer cells and the possible mechanism of action
}

\author{
ABDULMAJEED A. BAHMAN ${ }^{1 *}$, MOHAMED SALAH I. ABAZA ${ }^{1 *}$, \\ SARAH I. KHOUSHIASH ${ }^{1}$ and RAJAA J. AL-ATTIYAH ${ }^{2}$ \\ ${ }^{1}$ Molecular Biology Program, Department of Biological Sciences, Faculty of Science, \\ ${ }^{2}$ Department of Microbiology and Immunology, Faculty of Medicine, Kuwait University, 13060 Safat, State of Kuwait
}

Received May 23, 2017; Accepted May 21, 2018

DOI: $10.3892 / \mathrm{ijmm} .2018 .3725$

\begin{abstract}
Sorafenib (Nexavar, BAY43-9006 or Sora) is the first molecular targeted agent that has exhibited significant therapeutic benefits in advanced hepatocellular carcinoma (HCC). However, not all HCC patients respond well to Sora and novel therapeutic strategies to optimize the efficacy of Sora are urgently required. Plant-based drugs have received increasing attention owing to their excellent chemotherapeutic and chemopreventive activities; they are also well tolerated, non-toxic, easily available and inexpensive. It is well known that certain biologically active natural products act synergistically with synthetic drugs used in clinical applications. The present study aimed to investigate whether a combination therapy with natural phenolic compounds (NPCs), including curcumin (Cur), quercetin (Que), kaempherol (Kmf) and resveratrol (Rsv), would allow a dose reduction of Sora without concomitant loss of its effectiveness. Furthermore, the possible molecular mechanisms of this synergy were assessed. The hepatic cancer cell lines Hep3b and HepG2 were treated with Sora alone or in combination with NPCs in concomitant, sequential, and inverted sequential regimens. Cell proliferation, cell cycle, apoptosis and expression of proteins associated with the cell cycle and apoptosis were investigated. NPCs markedly potentiated the therapeutic efficacy of Sora in a sequence-, type-, NPC dose- and cell line-dependent manner. Concomitant treatment with Sora and Cur [sensitization ratio $(\mathrm{SR})=28$ ], Kmf $(\mathrm{SR}=18)$ or Que $(\mathrm{SR}=8)$ was associated with
\end{abstract}

Correspondence to: Professor Mohamed Salah I. Abaza, Molecular Biology Program, Department of Biological Sciences, Faculty of Science, Kuwait University, 13060 Safat, State of Kuwait E-mail: mohammed.abaza@ku.edu.kw

*Contributed equally

Key words: human hepatic cancer cells, sorafenib, natural phenolic compounds, sequence-dependent anticancer effects, molecular mechanisms the highest SRs in Hep3b cells. Rsv markedly potentiated the effect of Sora $(S R=17)$ on Hep3b cells when administered in a reverse sequential manner. By contrast, Rsv and Que did not improve the efficacy of Sora against HepG2 cells, while concomitant treatment with $\mathrm{Cur}(\mathrm{SR}=10)$ or $\mathrm{Kmf}(\mathrm{SR}=4.01)$ potentiated the cytotoxicity of Sora. Concomitant treatment with Sora and Cur or Kmf caused S-phase and G2/M phase arrest of liver cancer cells and markedly induced apoptosis compared with mono-treatment with Sora, Cur or Kmf. Concomitant treatment with Sora and Cur reduced the protein levels of cyclins A, B2 and D1, phosphorylated retinoblastoma and B-cell lymphoma $(\mathrm{Bcl})$ extra-large protein. By contrast, Sora and Cur co-treatment increased the protein levels of Bcl-2-associated X protein, cleaved caspase- 3 and cleaved caspase-9 in a dose-dependent manner. In conclusion, concomitant treatment with Sora and Cur or Kmf appears to be a potent and promising therapeutic approach that may control hepatic cancer by triggering cell cycle arrest and apoptosis. Additional studies are required to examine the potential of combined treatment with Sora and NPCs in human hepatic cancer and other solid tumor types in vivo.

\section{Introduction}

Hepatocellular carcinoma (HCC) is the most common type of primary liver tumor, accounting for $\sim 80 \%$ of all cases, with cholangiocarcinoma being the second most common ( $\sim 10 \%$ of cases). HCC is the fifth most common cancer type in the world and is responsible for $>600,000$ deaths per annum (1). The majority of patients with HCC die within 1 year of diagnosis. The disease is often diagnosed at a late stage when potentially curative therapies are less effective. For these patients, medical treatments, including chemotherapy, chemoembolization, ablation and proton beam therapy, remain ineffective. Most patients develop disease recurrence that rapidly progresses to advanced stages with vascular invasion and multiple intrahepatic metastases, and their 5-year survival rate is only 7\%. Although the prognosis of HCC patients with surgically resectable, localized tumors is better, their 5-year survival rates have been reported to only range from 15 to $39 \%$ (2). 
Important factors for HCC development are, among others, angiogenesis and signaling cascades regulating cell proliferation such as the Raf/MAPK kinase/MAPK pathway, which is activated in numerous hepatic carcinoma-derived cell lines and tumor samples (3). Current research on drug development aims at inhibition of the MAPK pathway as exemplified by sorafenib (Sora), a potent Raf kinase inhibitor, which causes tumor regression in HCC models and prolongs survival in HCC patients (4).

Sora, an oral multiple kinase inhibitor, is the first and only molecular targeted medicine approved by the U.S. Food and Drug Administration (FDA) for advanced HCC, and it is now a standard treatment. It significantly inhibits the activities of multiple tyrosine and serine/threonine kinases, as well as tumor angiogenesis, cell proliferation and apoptosis to exert its anticancer activity (5). However, in the clinic, Sora produces relatively low tumor response rates in the majority of $\mathrm{HCC}$ patients and is beneficial in only $\sim 30 \%$ of patients (4).

Sora treatment has severe toxicity, leading to adverse events including hand-foot skin reactions, diarrhea, hyperbilirubinemia, fatigue, anorexia and gastrointestinal bleeding. Even with treatment, the survival of certain patients is short (6). Owing to these toxicities, a large percentage of patients require a dose reduction or termination of treatment (7). In addition, in most patients who initially responded to Sora, tumor recurrence and progression often occurred after a few months of Sora therapy (8). Furthermore, no alternative effective therapeutic regimens are available after the failure of treatment with Sora. Modulation of the activity of Sora, which may lessen its toxicity, is therefore a desirable goal.

Certain natural products are excellent chemotherapeutic and chemopreventive agents, and $\sim 70 \%$ of the current anticancer drugs are derived from natural products $(9,10)$. They tend to be well tolerated, non-toxic, easily available and inexpensive (11). It is well known that biologically active natural produces may act synergistically with chemotherapeutic drugs used in clinical applications. The aim of the present study was to investigate the potential of natural phenolic compounds (NPCs), including curcumin (Cur), quercetin (Que), kaempherol (Kmf) and resveratrol (Rsv), in potentiating the anticancer effects of the multikinase inhibitor Sora on hepatic cancer cell lines, identify the best drug combinations and best combination strategies to potentiate the anticancer effect of Sora on hepatic cancer, and examine the possible mechanisms of action.

\section{Materials and methods}

Cell culture. The hepatic cancer cell lines, Hep3b and HepG2 and the normal human fibroblast cell line CRL1554 were obtained from the American Type Culture Collection (Manassas, VA, USA). HepG2 and Hep3b cells were grown in Eagle's minimal essential medium (EMEM; Gibco; Thermo Fisher Scientific, Inc., Waltham, MA, USA) containing $10 \%$ fetal bovine serum (FBS; Gibco; Thermo Fisher Scientific, Inc.) in a $5 \% \mathrm{CO}_{2}$ incubator at $37^{\circ} \mathrm{C}$. HepG2 cells, which were originally thought to be a HCC cell line $(12,13)$, have been misidentified and are considered to be a hepatoblastoma cell line (14). CRL1554 cells were grown in Dulbecco's modified Eagle's medium (DMEM; Gibco; Thermo Fisher Scientific, Inc.) containing 10\% FBS in a $\mathrm{CO}_{2}$ incubator at $37^{\circ} \mathrm{C}$. Penicillin/streptomycin (Sigma-Aldrich;
Merck KGaA, Darmstadt, Germany), gentamicin (Gibco; Thermo Fisher Scientific, Inc.), L-glutamine (Fluka; Honeywell Labs, Muskegon, MI, USA) and sodium hydrogen carbonate were added to all media during preparation. The NPCs were all obtained from Sigma-Aldrich (Merck KGaA) and included homoharringtonine (HHG), Kmf, Cur, Que, Rsv, hesperetin (Hsp), betulinic acid (BetA), indol-3-carbinol (IC3), coumarin (Cmr), sulanidac (Sul), irinotecan (Irt), lycopene (Lyp), silibinin (Sil) and sinirgin (Snn).

Dose-dependent anti-proliferative effect of a panel of NPCs on CRL1554 normal human fibroblasts. The growth inhibitory effects of a panel of 14 NPCs (Kmf, Cur, Que, Rsv, HHG, Hsp, BetA, IC3, Cmr, Sul, Irt, Lyc, Sil and Snn) on CRL1554 normal human fibroblast cells was determined by an MTT assay. CRL1554 cells were seeded into 96-well flat-bottomed plates at $27 \times 10^{3}$ cells/well and incubated at $37^{\circ} \mathrm{C}$ for $18 \mathrm{~h}$. On the following day, the medium was removed, the cells were washed with Hank's balanced salt solution (HBSS; $100 \mu \mathrm{l} /$ well), and treated with various concentrations of NPCs $(20,40,60,80,100,120,140$ and $160 \mu \mathrm{M})$ for $72 \mathrm{~h}$. The cells were then washed twice with HBSS and $100 \mu 1$ medium plus $20 \mu \mathrm{l}$ MTT solution $(5 \mathrm{mg} / \mathrm{ml})$ in PBS was added to each well, followed by incubation at $37^{\circ} \mathrm{C}$ for $4 \mathrm{~h}$. The supernatants were aspirated and $200 \mu \mathrm{l}$ dimethyl sulfoxide was added to dissolve the formazan crystals. Finally, the absorbance was measured spectrophotometrically using a multiwell spectrophotometer (Thermo/Lab-systems 352Multiskan MS Microplate Reader; Artisan Technology Group, Champaign, IL, USA) at two wavelengths ( $\lambda=490$ for absorbance/detection and $650 \mathrm{~nm}$ as a reference wavelength).

Schedule-dependent anti-proliferative effect of combined treatments with Sora and NPCs (Cur, Kmf, Que and Rsv) on human hepatic cancer cell lines Hep3b and Hep G2. To determine the schedule dependency of the combined treatments with Sora and NPCs, Hep3b and HepG2 cells were seeded into 96 -well flat-bottomed plates at $27 \times 10^{3}$ cells/well and incubated for $18 \mathrm{~h}$. The medium was removed and the cells were washed with HBSS (100 $\mu$ l/well). For sequential treatments, Sora $(0.25-10 \mu \mathrm{M})$ was added and the cells were incubated at $37^{\circ} \mathrm{C}$ for $24 \mathrm{~h}$. The next day, the plates were washed and an NPC [Kmf, Cur or Que (60 or $120 \mu \mathrm{M})$ or Rsv (40 or $80 \mu \mathrm{M})$ ] was added, followed incubation at $37^{\circ} \mathrm{C}$ for $48 \mathrm{~h}$.

For inverted sequential treatments, an NPC [Kmf, Cur or Que $(60$ or $120 \mu \mathrm{M})$ or Rsv $(40$ or $80 \mu \mathrm{M})]$ was added, followed by incubation at $37^{\circ} \mathrm{C}$ for $24 \mathrm{~h}$. The next day, the plates were washed and Sora (0.25-10 $\mu \mathrm{M})$ was added, followed by incubation for $48 \mathrm{~h}$. For simultaneous treatments, Sora $(0.25-10 \mu \mathrm{M})$ and an NPC [Kmf, Cur or Que (60 or $120 \mu \mathrm{M})$ or Rsv (40 or $80 \mu \mathrm{M})$ ] were added simultaneously, followed by incubation at $37^{\circ} \mathrm{C}$ for $72 \mathrm{~h}$. Cell growth was monitored as mentioned above.

Cell cycle analysis. To investigate the detailed mechanism of the underlying antiproliferative activity of Sora, Cur/Kmf and their simultaneous combinations, flow cytometry was used to determine the distribution of cells in the different cell cycle phases $\left(\mathrm{G}_{0} / \mathrm{G}_{1}, \mathrm{~S}\right.$ and $\left.\mathrm{G}_{2} / \mathrm{M}\right)$ by measuring the DNA content 
of the nuclei labeled with propidium iodide (PI), as described previously (15). In brief, cells $\left(2.5 \times 10^{5}\right.$ cells/well) were seeded into 24-well plates and incubated in a $\mathrm{CO}_{2}$ incubator at $37^{\circ} \mathrm{C}$ for $18 \mathrm{~h}$, followed by mono- or simultaneous combined treatment with Sora $(5 \mu \mathrm{M})$ and Cur or $\mathrm{Kmf}(200$ and $400 \mu \mathrm{M})$ with incubation at $37^{\circ} \mathrm{C}$ for $72 \mathrm{~h}$. The cells were then processed using a DNA-prep kit and a DNA-Prep EPICS workstation (Beckman Coulter, Inc., Brea, CA, USA). In brief, the cells were treated with a non-ionic detergent that was used as a cell membrane-permeabilizing agent, followed by addition of PI and RNase A (Sigma-Aldrich; Merck KGaA) and incubation at $15-20^{\circ} \mathrm{C}$ for $15 \mathrm{~min}$. The cells were re-suspended in binding buffer at a concentration of $3-10 \times 10^{6}$ cells $/ \mathrm{ml}$ for optimal staining. Fluorescence was measured with a flow cytometer (FC500; Beckman Coulter, Miami, FL, USA), and the percentage of cells in the different cell cycle phases was calculated using the phoenix statistical software package, advanced DNA cell cycle software, version 4, 0, 0, 307-MultiCycle for Windows (Phoenix Flow Systems, San Diego, CA, USA).

\section{Cell death analysis}

DNA fragmentation assay. Induction of apoptosis was monitored using a DNA fragmentation assay according to the manufacturer's instructions (Abcam Apoptotic DNA Ladder Detection kit; Abcam, Cambridge, MA, USA). In brief, cells were seeded into 24 -well plates at $2.5 \times 10^{5}$ cells/well and incubated in a $\mathrm{CO}_{2}$ incubator at $37^{\circ} \mathrm{C}$ for $18 \mathrm{~h}$, followed by single and simultaneous treatment with Cur or $\mathrm{Kmf}$ $(200$ and $400 \mu \mathrm{M})$ plus Sora $(5 \mu \mathrm{M})$ and incubation at $37^{\circ} \mathrm{C}$ for $72 \mathrm{~h}$. The cells were then trypsinized, harvested, washed, pelleted and lysed with Tris + EDTA lysis buffer $(35 \mu \mathrm{l})$. Enzyme A Solution (RNase; $5 \mu$ l) was added, followed by incubation at $37^{\circ} \mathrm{C}$ for $10 \mathrm{~min}$. Enzyme B Solution (proteinase; $5 \mu \mathrm{l}$ ) was then added, followed by incubation at $50^{\circ} \mathrm{C}$ for $30 \mathrm{~min}$. Ammonium acetate solution $(5 \mu \mathrm{l})$ plus isopropanol $(50 \mu \mathrm{l})$ were added to each sample, followed by incubation at $-20^{\circ} \mathrm{C}$ for $10 \mathrm{~min}$. Finally, the DNA was pelleted at $13,000 \mathrm{x} \mathrm{g}$, for $10 \mathrm{~min}$ at $4^{\circ} \mathrm{C}$, washed with $0.5 \mathrm{ml} 70 \%$ ethanol and suspended in $30 \mu \mathrm{l}$ DNA suspension buffer. The extracted DNA samples were loaded into a $1.2 \%$ agarose gel and subjected to electrophoresis using running buffer containing $1.35 \mu \mathrm{g} / \mathrm{ml}$ ethidium bromide along with loading marker (1 kb DNA Ladder) at $5 \mathrm{~V} / \mathrm{cm}$ for $1 \mathrm{~h}$. Ethidium bromide-stained DNA bands were visualized using trans-illumination with ultraviolet light.

Annexin V-fluorescein isothiocyanate (FITC) and PI double staining assay. The apoptotic cells were estimated by determing the levels of phosphatidylserine on cell surface. HepG2 and Hep 3 b cells were seeded into 24 -well plates at $2.5 \times 10^{5}$ cells $/$ well and incubated in a $\mathrm{CO}_{2}$ incubator at $37^{\circ} \mathrm{C}$ for $18 \mathrm{~h}$. The cells were then simultaneously treated with Cur and Kmf (200 or $400 \mu \mathrm{M})$ and Sora $(5 \mu \mathrm{M})$ for $72 \mathrm{~h}$, washed twice with HBSS, harvested by trypsinization and washed. Finally, the cells were double-stained using the Annexin V-FITC-FLOUS staining kit according to manufacturer's instructions (Roche Diagnostics $\mathrm{GmbH}$, Mannheim, Germany). In brief, Annexin V-FLOUS labeling solution containing Annexin V-FITC and PI (100 $\mu \mathrm{l})$ was added to treated and control cell groups, followed by incubation at $15-20^{\circ} \mathrm{C}$ for $15 \mathrm{~min}$. The cells $\left(1 \times 10^{6}\right.$ cells $\left./ \mathrm{ml}\right)$ were then re-suspended in binding buffer and fluorescence was monitored by flow cytometry (FC500; Beckman Coulter).

Mitochondrial membrane potential (MMP). The mitochondrial inner membrane is negatively charged as it is rich in negatively charged glycoproteins. A large accumulation of protons out of the inner membrane caused transmembrane potential. The MMP was monitored by an NIR Mitochondrial Membrane Potential Assay kit (Abcam) according to the manufacturer's protocol. In brief, cells $\left(2.5 \times 10^{5}\right.$ cells/well $)$ were seeded into 24-well plates and incubated in a $\mathrm{CO}_{2}$ incubator at $37^{\circ} \mathrm{C}$ for $18 \mathrm{~h}$. The cells were simultaneously treated with Cur or Kmf (200 or $400 \mu \mathrm{M})$ and Sora $(5 \mu \mathrm{M})$ for $72 \mathrm{~h}$. MitoNIR Dye $(200 \mathrm{X}, 5 \mu \mathrm{l} / \mathrm{ml})$ was added to each sample, followed by incubation at $37^{\circ} \mathrm{C}$ for $15-30 \mathrm{~min}$. Finally, the cells were pelleted and re-suspended in $1 \mathrm{ml}$ assay buffer, and the fluorescence intensity was monitored using flow cytometry in the FL4 channel $\left(\lambda_{\text {Excitation }} / \lambda_{\text {Emission }}=635 / 660 \mathrm{~nm}\right)$.

Western blot analysis. The expression of genes associated with the control of the cell cycle and apoptosis after mono- and simultaneous combined treatment with Sora $(5 \mu \mathrm{M})$ and Cur (200 or $400 \mu \mathrm{M}$ ) was monitored by western blot analysis. In brief, whole-cell protein extraction was performed using the Mammalian Cell \& Tissue Extraction kit (BioVision, Milpitas, CA, USA) according to the manufacturer's protocols. Protein concentrations were determined using the Protein assay kit II (Bio-Rad Laboratories, Inc., Hercules, CA, USA). Protein extracts $(60 \mu \mathrm{g})$ were mixed with $2 \mathrm{X}$ Laemmli sample loading buffer and loaded into gels $\left(\right.$ Criterion $^{\mathrm{TM}}$ TGX Stain-free ${ }^{\mathrm{TM}}$ Precast gels; Bio-Rad Laboratories, Inc.) along with Precision Plus Protein ${ }^{\mathrm{TM}}$ dual color standards pre-stained marker (Bio-Rad Laboratories, Inc.) and subjected to electrophoresis at $250 \mathrm{~V}$ for $25 \mathrm{~min}$. The bands were transferred onto low-fluorescence-polyvinylidene difluoride membranes using the Trans Blot ${ }^{\circledR}$ Turbo $^{\mathrm{TM}}$ system (Bio-Rad Laboratories, Inc.) for $7 \mathrm{~min}$, and the blots were checked using the complementary imaging system and software (Image $\mathrm{Lab}^{\mathrm{TM}}$ version 5). The membranes were washed 3 times for 5 min each with Tris-buffered saline containing 0.05\% Tween-20 (TBST) and the nonspecific binding sites were blocked by incubating with $5 \%$ bovine serum albumin-Tris-buffered saline Tween-20 buffer (BSA/TBST; Bio-Rad Laboratories, Inc.) at $37^{\circ} \mathrm{C}$ for $1 \mathrm{~h}$. The membranes were washed again and incubated at $4^{\circ} \mathrm{C}$ overnight with the following primary antibodies: Cyclin A2 rabbit monoclonal antibody (mAb) (E399; cat. no. ab32498), cyclin $\mathrm{B} 1 \mathrm{XP}^{\circledR}$ rabbit mAb (D5C10, cat. no. 12231), cyclin D1 rabbit mAb (92G2; cat. no. 2978), p27 ${ }^{\mathrm{Kip} 1} \mathrm{XP}^{\circledR}$ rabbit mAb (D69C12; cat. no. 3686), phospho-retinoblastoma protein (p-Rb), rabbit mAb (Ser780, C84F6; cat. no. 3590), cleaved caspase-3, rabbit mAb (Asp175, 5A1E; cat. no. 9664), cleaved caspase-9, rabbit mAb (Asp330, D2D4; cat. no. 7237), B-cell lymphoma 2-associated $\mathrm{X}$ protein (Bax), rabbit mAb (D2E11; cat. no. 5023), B-cell lymphoma extra-large protein (Bcl-xL),rabbit mAb (54H6; cat. no. 2764) and $\beta$-actin rabbit mAb (cat. no. 4967; Cell Signaling Technologies, Inc., Danvers, MA, USA) at 1:1,000 dilution in 5\% BSA-TBST. The membranes were washed and incubated with horseradish peroxidase-conjugated rabbit anti-mouse immunoglobulin $\mathrm{G}$ as the secondary antibody (Cell Signaling Technologies, Inc.) 
A a CRL1554
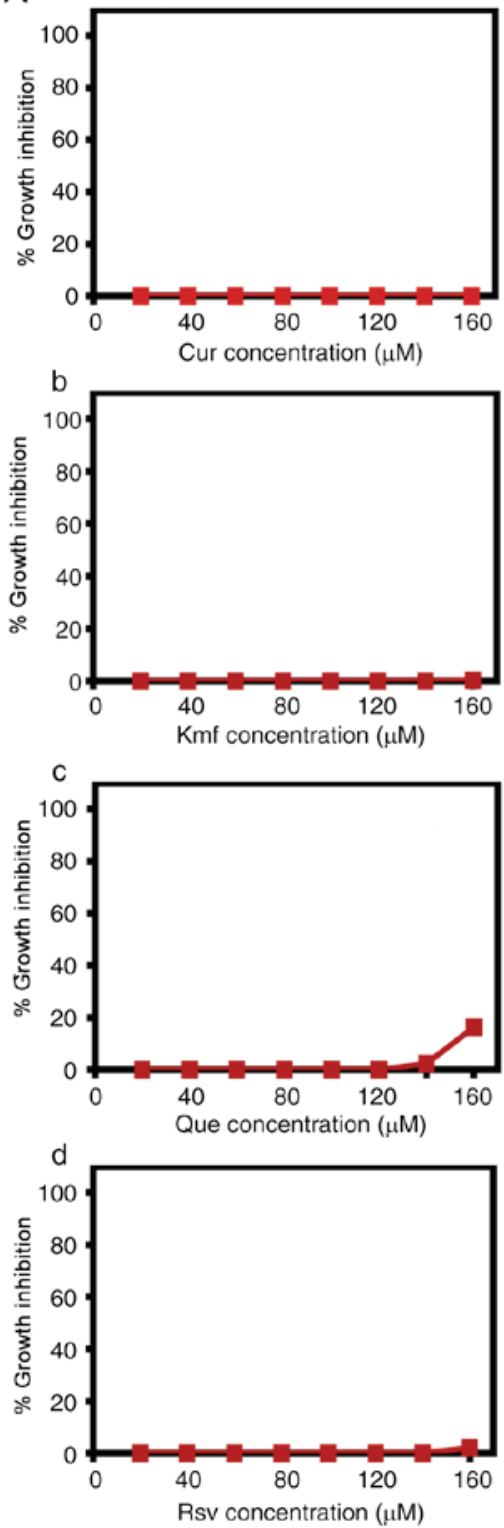

B a Нерзb
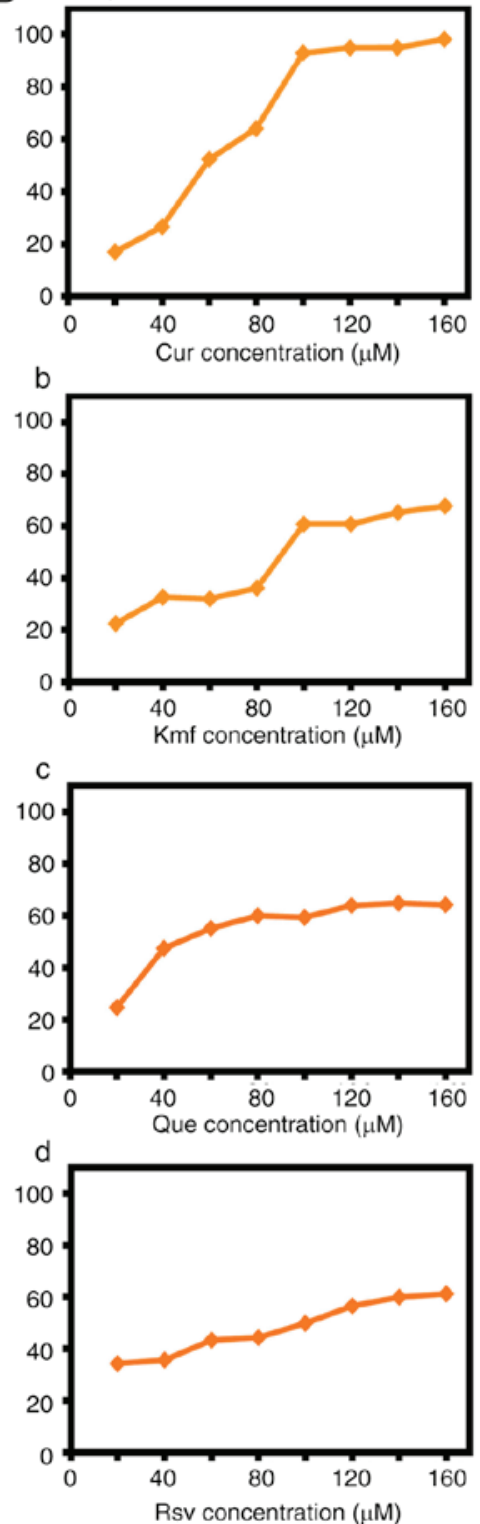

C a HepG2
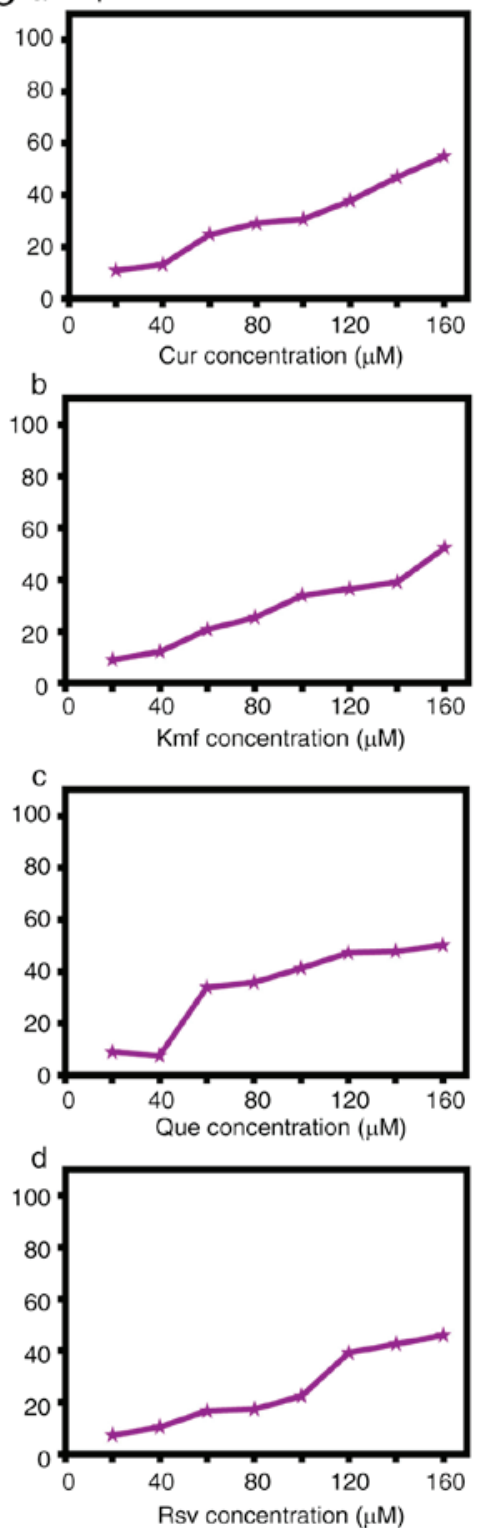

Figure 1. Dose-dependent anti-proliferative effect of (a) Cur, (b) Kmf, (c) Que and (d) Rsv (20-160 $\mu$ M) for 72 h on (A) CRL1554 normal human fibroblast, and (B) Hep3b and (C) HepG2 hepatic cancer cell lines. Cell growth was monitored using an MTT assay. Cur, curcumin; Kmf, kaempferol; Que, quercetin; Rsv, resveratrol.

at 1:2,000 dilutions in 5\% BSA-TBST at room temperature for $1 \mathrm{~h}$. The membranes were washed in TBST and stained using the Bio-Rad Clarity ${ }^{\mathrm{TM}}$ western enhanced chemiluminescence substrate mixture (Bio-Rad Laboratories, Inc.; $6 \mathrm{ml}$ peroxide solution $+6 \mathrm{ml}$ of Luminol/enhance solution) in the dark for $5 \mathrm{~min}$. The bands were detected using the ChemiDoc ${ }^{\mathrm{TM}}$ MP imaging system and Image $\mathrm{Lab}^{\mathrm{TM}}$ software, version 5 (Bio-Rad Laboratories, Inc). Signal intensities of the respective bands were quantified with a GS-800 calibrated imaging densitometer (Bio-Rad Laboratories, Inc.).

Statistical analysis. Statistical analyses were performed using SPSS v. 23 (IBM Corp., Armonk, NY, USA) and the results are expressed as the mean \pm standard error of the mean. Statistical significance of differences between the control and treated groups was determined by one-way analysis of variance and Fisher's least-significant differences test. $\mathrm{P}<0.05$ was considered to indicate a statistically significant difference between groups.

\section{Results}

\section{Inhibition studies}

Dose-dependent-anti-proliferative effects of Sora and NPCs on CRL1554 normal human fibroblast cells. To assess the potential growth inhibitory effect of Sora and NPCs, CRL1554 normal human fibroblast cells were treated with various concentrations of Sora (0.25-10 $\mu \mathrm{M})$ and NPCs $(20-160 \mu \mathrm{M})$, including Kmf, Que, Rsv, Cur, Irt, Sil, Snn, Sul, Lyp, Hsp, BetA, $\mathrm{Cmr}$, I3C and $\mathrm{HHG}$, for $72 \mathrm{~h}$. Sora exhibited a marked growth inhibitory effect (5-100\%), while the NPCs exerted differential anti-proliferative effects on CRL1554 cells. The results of the 14 tested NPCs were classified into two groups based on their growth inhibitory effect: i) NPCs exerting no or little effect (0.0-20\% cytotoxicity) on CRL1554 cells, including Cur (0.0\%; Fig. 1A-a), Kmf (0.0-1.1\%; Fig. 1A-b), Que (0.0-16.2\%; Fig. 1A-c) and Rsv (0.0-3.3\%; Fig. 1A-d), as well as Hsp $(0.0-4.4 \%)$, Sin (0.0-5.54\%), Snn (0.0-7.3\%), I3C (0.2-9.2\%), 
A a Hep3b
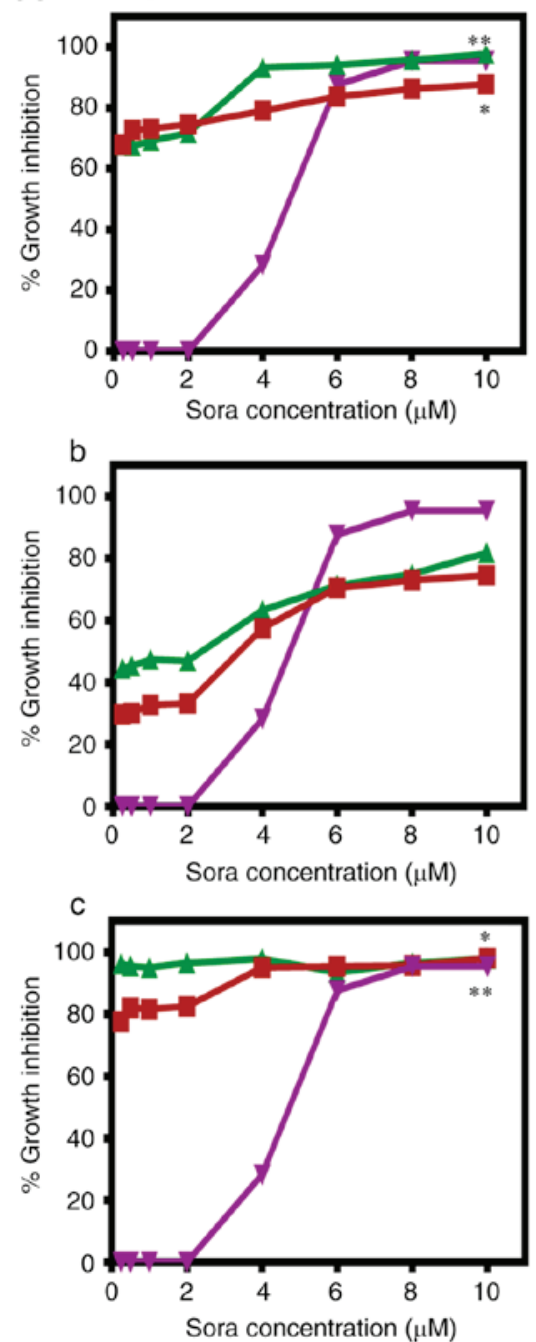

B a HepG2
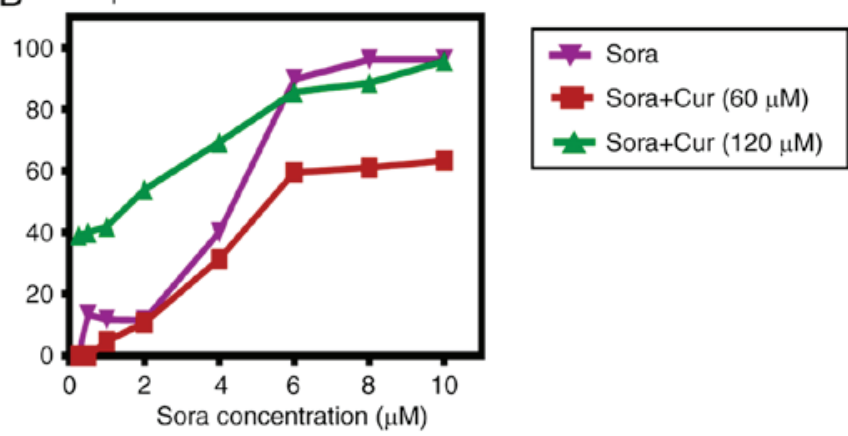
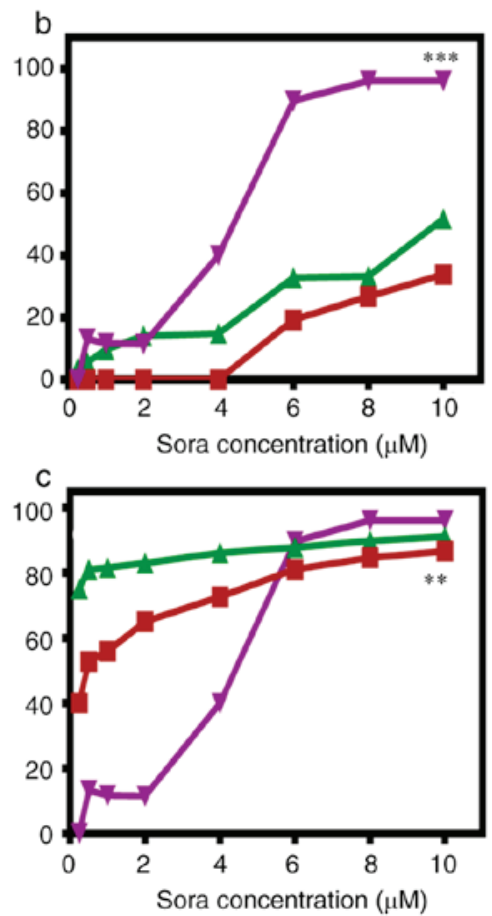

Figure 2. Sequence-dependent anti-proliferative effect of combined treatment with Sora and Cur on (A) Hep3b and (B) HepG2 hepatic cancer cell lines. The cells were treated with a combination of Sora $(5 \mu \mathrm{M})$ and Cur $(60$ or $120 \mu \mathrm{M})$ in (a) a sequential, (b) inverted sequential and (c) concomitant manner. Cell growth was determined by an MTT assay. Sora, sorafenib; Cur, curcumin; UT, untreated, ${ }^{*} \mathrm{P}<0.05$ (Sora $+60 \mu \mathrm{M}$ Cur) vs. Sora, ${ }^{* *} \mathrm{P}<0.05$ (Sora $+120 \mu \mathrm{M}$ Cur) vs. Sora, ${ }^{* * *} \mathrm{P}<0.05$ Sora vs. (Sora $+60 \mu \mathrm{M}$ Cur or $120 \mu \mathrm{M}$ Cur).

and Cmr (7.4-11.3\%; results not shown), and ii) NPCs exerting marked growth inhibitory effects on CRL1554, including Lyp (40.0-67.0\%), Irt (45.0-82.0\%), Sul (39.0-98.0\%), BetA (69.0-98.0\%) and HHG (99.0-100.0\%; results not shown). Based on the growth inhibitory effects of the tested NPCs, further research efforts were focused on testing the potential of Cur, Que, Rsv, and Kmf to potentiate the lethality of Sora on hepatic cancer cells, as they exhibited little or no growth inhibitory effect against CRL1554 (Fig. 1A).

Dose-dependent anti-proliferative effects of Cur, Kmf, Que and Rsv on human hepatic cancer cell lines. To assess the growth inhibitory effect of the selected NPCs (Cur, Kmf, Que and Rsv) on hepatic cancer cell lines, Hep3b and HepG2 cells were treated with various concentrations of these compounds. The tested NPCs inhibited the growth of Hep3b cells as follows: Cur [concentration causing a 50\% reduction in the amount of cells $\left.\left(\mathrm{IC}_{50}\right)=60 \mu \mathrm{M}\right], \mathrm{Kmf}\left(\mathrm{IC}_{50}=95 \mu \mathrm{M}\right)$, Que $\left(\mathrm{IC}_{50}=40 \mu \mathrm{M}\right)$, and Rsv $\left(\mathrm{IC}_{50}=100 \mu \mathrm{M}\right)$ (Fig. 1B). The tested NPCs exhibited lower anticancer effects on HepG2 than on Hep3b cells.
The anticancer effect on HepG2 cells was as follows: Cur $\left(\mathrm{IC}_{50}=140 \mu \mathrm{M}\right), \mathrm{Kmf}\left(\mathrm{IC}_{50}=155 \mu \mathrm{M}\right)$, Que $\left(\mathrm{IC}_{50}=140 \mu \mathrm{M}\right)$ and $\operatorname{Rsv}\left(\mathrm{IC}_{50}=120 \mu \mathrm{M}\right)$ (Fig. 1C).

Sequence and dose-dependent anti-proliferative effects of combined treatment with Sora and Cur, Kmf, Que or Rsv on human hepatic cancer cell lines. The aim was to test the ability of the NPCs (Cur, Kmf, Que and Rsv) to synergize with Sora in order to enhance its anticancer activity against human hepatic cancer cell lines Hep3b and HepG2. Three different administration schedules: Sequential, inverted sequential and simultaneous were tested. The obtained results are summarized in Figs. 2-5 and Tables I and II. The tested NPCs potentiated the lethality of Sora in the following order: Cur $>$ $\mathrm{Kmf}>\mathrm{Rsv}>$ Que, in a dose-, hepatic cancer cell type-, NPC type- and administration schedule-dependent manner.

Flow cytometric analysis of the cell cycle in hepatic cancer cell lines following single and combined treatment with Sora and Cur or Kmf 

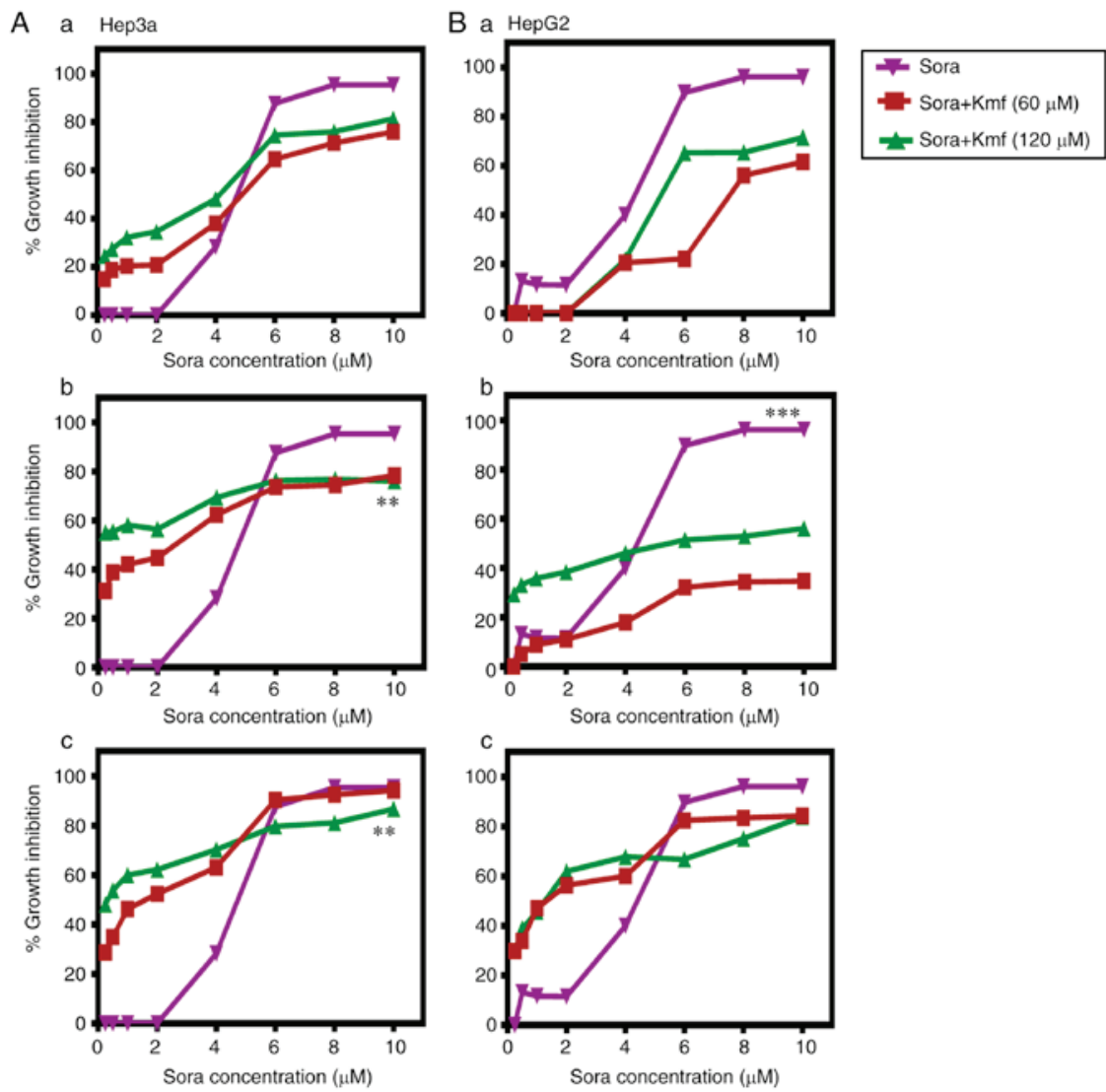

Figure 3. Sequence-dependent anti-proliferative effect of combined treatment with Sora and Kmf on (A) Hep3b and (B) HepG2 hepatic cancer cell lines. The cells were treated with a combination of Sora $(5 \mu \mathrm{M})$ and $\mathrm{Kmf}(60$ and $120 \mu \mathrm{M})$ in (a) a sequential, (b) inverted sequential and (c) concomitant manner. Cell growth was determined by an MTT assay. Kmf, kaempferol; Sora, sorafenib; UT, untreated, ${ }^{* *} \mathrm{P}<0.05$ (Sora $+120 \mu \mathrm{M} \mathrm{Kmf}$ ) vs. Sora, ${ }^{* * * *} \mathrm{P}<0.05$ Sora vs. (Sora $+60 \mu \mathrm{M} \mathrm{Kmf}$ ).

A. Hep3b
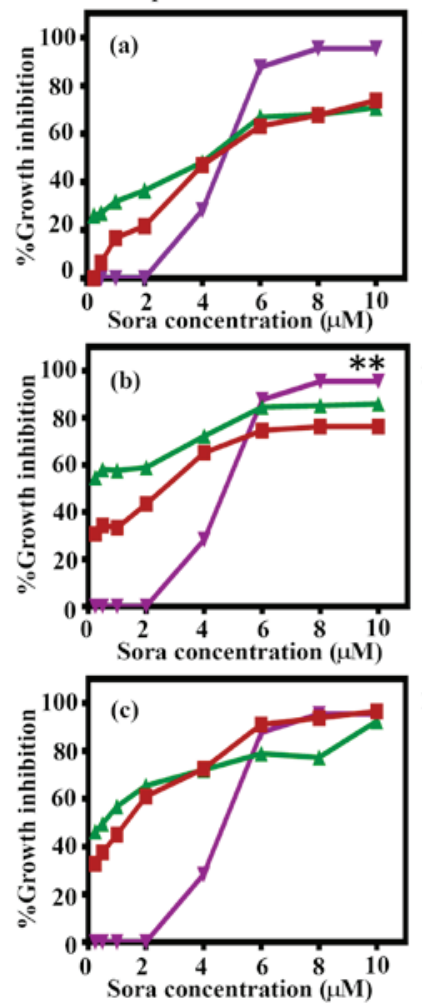

B. HepG2

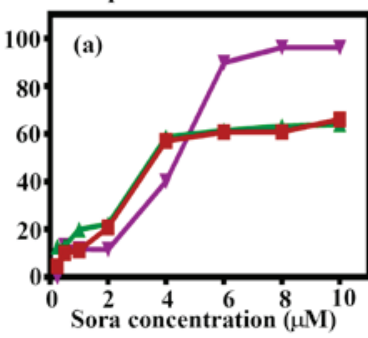

- Sora

- $\mathrm{Cora}+$ Que $(60 \mu \mathrm{M})$

\pm Sora + Que $(120 \mu \mathrm{M})$
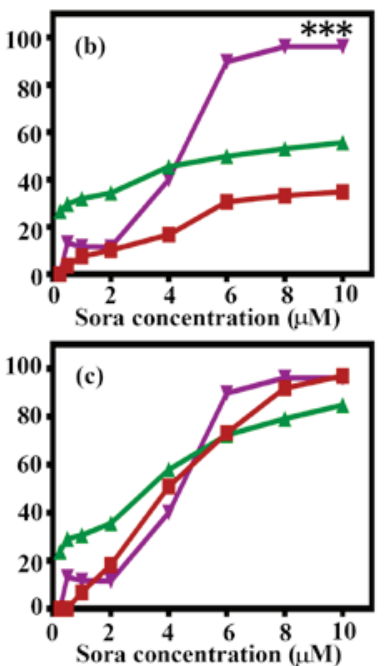

Figure 4. Sequence-dependent anti-proliferative effect of combined treatment Sora and Que on (A) Hep3b and (B) HepG2 hepatic cancer cell lines. The cells were treated with a combination of Sora $(5 \mu \mathrm{M})$ and Que $(60$ and $120 \mu \mathrm{M})$ in (a) a sequential, (b) inverted sequential and (c) concomitant manner. Cell growth was determined by an MTT assay. Que, quercetin; Sora, sorafenib; UT, untreated, ${ }^{* *} \mathrm{P}<0.05$ (Sora $+120 \mu \mathrm{M}$ Que) vs. Sora, ${ }^{* * *} \mathrm{P}<0.05$ Sora vs. (Sora $+60 \mu \mathrm{M}$ Que). 

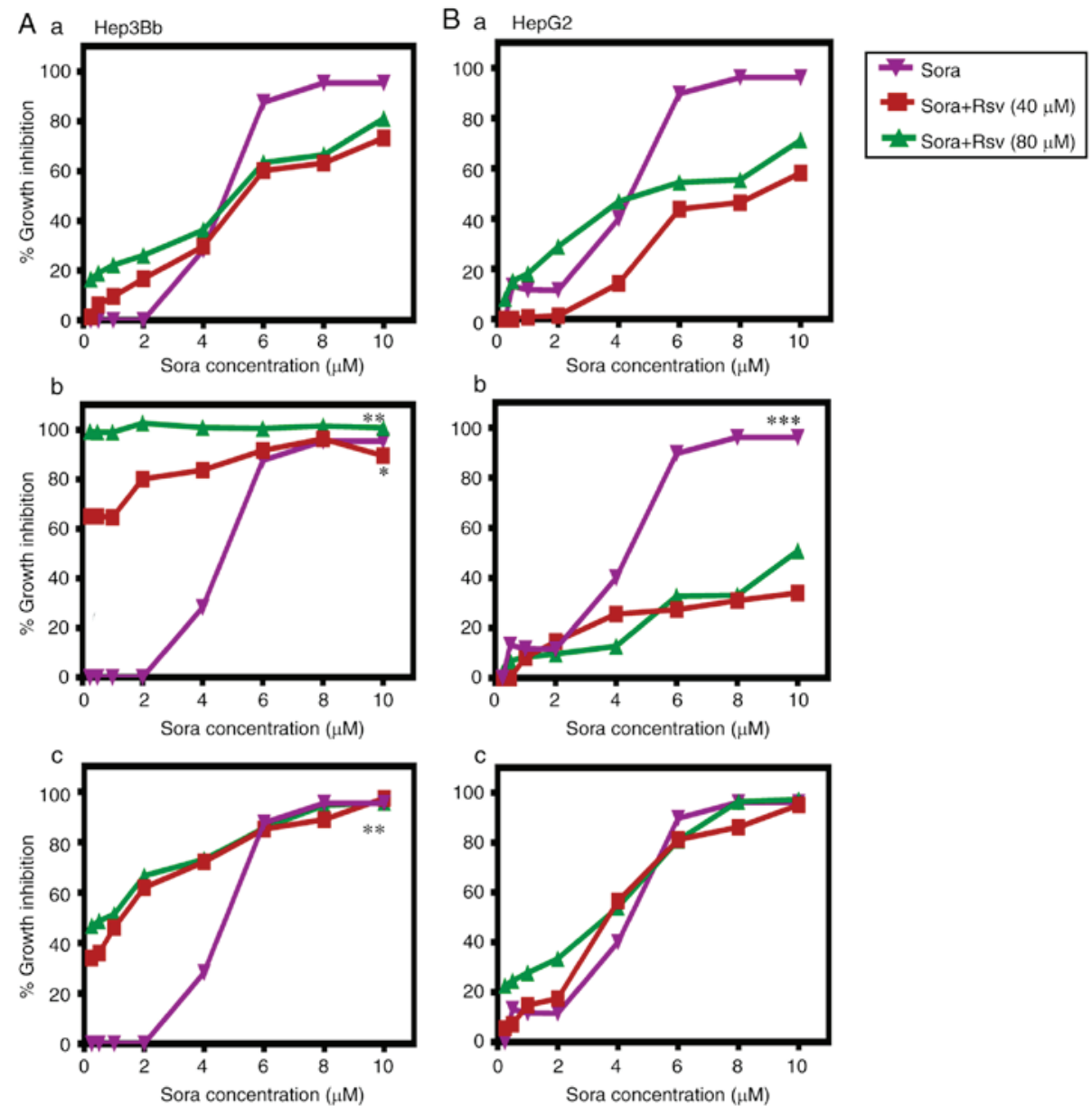

Figure 5. Sequence-dependent anti-proliferative effect of combined treatment with Sora and Rsv on (A) Hep3b and (B) HepG2 hepatic cancer cell lines. The cells were treated with a combination of Sora $(5 \mu \mathrm{M})$ and Rsv $(40$ or $80 \mu \mathrm{M})$ in (a) a sequential, (b) inverted sequential and (c) concomitant manner. Cell growth was monitored by MTT assay. Sora, sorafenib; UT, untreated; Rsv, resveratrol, " $\mathrm{P}<0.05$ (Sora $+40 \mu \mathrm{M}$ Rsv) vs. Sora, " $\mathrm{P}<0.05$ (Sora $+80 \mu \mathrm{M}$ Rsv) vs. Sora,

${ }^{* * * *} \mathrm{P}<0.05$ Sora vs. (Sora $+40 \mu \mathrm{M}$ Rsv or $80 \mu \mathrm{M}$ Rsv).

Single and combined treatment with Sora and Cur. Treatment with Sora $(5 \mu \mathrm{M})$ increased the population of Hep3b cells in the $\mathrm{S}$-phase $(\mathrm{P}=0.151)$ accompanied with a decrease in the population of cells in the $\mathrm{G}_{0} / \mathrm{G}_{1}(\mathrm{P}=0.145)$ and the $\mathrm{G}_{2} / \mathrm{M}$-phase $(\mathrm{P}=0.001)$ compared to untreated (UT) (Fig. 6A). By contrast, Cur $(200 \mu \mathrm{M})$ increased the population of Hep3b cells in the S-phase $(P=0.003)$ and the $G_{2} / M$-phase $(P=0.001)$ with a concomitant decrease in the $G_{0} / G_{1}$-phase population $(P=0.003)$ compared to UT (Fig. 6A). In addition, Cur (400 $\mu \mathrm{M})$ markedly increased the population of Hep3b cells in the $\mathrm{G}_{2} / \mathrm{M}$-phase $(\mathrm{P}=0.001)$ but only slightly reduced the $\mathrm{S}$-phase population $(\mathrm{P}=0.776)$ with a corresponding decrease in the number of cells in $\mathrm{G}_{0} / \mathrm{G}_{1}$-phase $(\mathrm{P}=0.098)$ compared to UT. Cur $(400 \mu \mathrm{M})$ induced apoptosis in Hep3b cells (\% subG1=32.6 vs . 6.7 for UT) (Fig. 6A). Furthermore, simultaneous combined treatment with Sora $(5 \mu \mathrm{M})$ and Cur $(200 \mu \mathrm{M})$ increased the population of Hep3b cells in the $\mathrm{S}$-phase $(\mathrm{P}=0.041)$ and the $\mathrm{G}_{2} / \mathrm{M}$-phase $(\mathrm{P}=0.049)$ with a corresponding decrease in the $\mathrm{G}_{0} / \mathrm{G}_{1}$-phase population ( $\mathrm{P}=0.007$ ) compared to UT (Fig. $6 \mathrm{~A}$ ). Simultaneous combined treatment with Sora $(5 \mu \mathrm{M})$ and Cur $(400 \mu \mathrm{M})$ greatly increased the population of Hep3b cells in the $G_{2} / M$-phase $(P=0.003)$ and slightly increased the population of cells in the $G_{0} / G_{1}$-phase $(P=0.835)$, with a concomitant decrease in the cell population in $\mathrm{S}$-phase $(\mathrm{P}=0.001)$ compared to UT. This drug combination induced apoptosis in Hep3b cells (\% subG1 $=26.4$ vs. $6.7 \%$ for UT; Fig. 6A).

Simultaneous combined treatment of Hep3b with Sora $(5 \mu \mathrm{M})$ and Cur $(200 \mu \mathrm{M})$ growth arrested the cells in both S-phase $(\mathrm{P}=0.365)$ and $\mathrm{G}_{2} / \mathrm{M}$-phase $(\mathrm{P}=0.01)$ compared with the cells treated with Sora. On the other hand, cells treated with Sora alone $(5 \mu \mathrm{M})$ were significantly growth arrested in $\mathrm{G}_{0} / \mathrm{G}_{1}$-phase $(\mathrm{P}=0.009)$ compared to cells treated with simultaneous combined treatment of Sora $(5 \mu \mathrm{M})$ and Sora $(200 \mu \mathrm{M}$; Fig. 6A).

Simultaneous combined treatment of Hep3b with Sora $(5 \mu \mathrm{M})$ and Cur $(200 \mu \mathrm{M})$ resulted in an increase in the number of cells in the $\mathrm{G}_{0} / \mathrm{G}_{1}$-phase $(\mathrm{P}=0.024)$ and $\mathrm{G}_{2} / \mathrm{M}$-phase $(\mathrm{P}=0.816)$ compared to cells treated with Cur $(200 \mu \mathrm{M})$. On the other hand, Cur $(200 \mu \mathrm{M})$ growth arrested Hep3b in S-phase $(\mathrm{P}=0.051)$ compared with the combined treatment (Fig. 6A).

Simultaneous combined treatment of Hepb3 with Sora $(5 \mu \mathrm{M})$ and Cur $(400 \mu \mathrm{M})$ significantly increased cell population in the $\mathrm{G}_{2} / \mathrm{M}$-phase $(\mathrm{P}=0.0001)$, but slightly increased the number of cells in $\mathrm{G}_{0} / \mathrm{G}_{1}$-phase $(\mathrm{P}=0.248)$ compared to single treatment with Sora $(5 \mu \mathrm{M})$. On the other hand, Sora $(5 \mu \mathrm{M})$ significantly increased number of cells in the S-phase $(\mathrm{P}=0.0001)$ compared to the combined treatment (Fig. 6A). Furthermore, this combined treatment significantly increased the number of arrested cells in the $G_{0} / G_{1}$-phase $(P=0.045)$ 
Table I. $\mathrm{IC}_{50,60,70}$, SR, P-values of single and combined treatment with Sora and Cur or Kmf in human hepatic cancer cell lines.

\begin{tabular}{|c|c|c|c|c|c|c|}
\hline \multirow[b]{2}{*}{$\begin{array}{l}\text { Single and combined treatment } \\
\text { with Sora and Cur }\end{array}$} & \multicolumn{3}{|c|}{ Hep3b } & \multicolumn{3}{|c|}{ HepG2 } \\
\hline & $\begin{array}{l}\mathrm{IC}_{50,60, \text { etc. }} \\
\quad(\mu \mathrm{M})\end{array}$ & SR & P-value & $\begin{array}{l}\mathrm{IC}_{50,60, \text { etc. }} \\
\quad(\mu \mathrm{M})\end{array}$ & SR & P-value \\
\hline \multicolumn{7}{|c|}{ 1. Sequential treatment with Sora and Cur: Sora ( $24 \mathrm{~h}$ ) followed by Cur ( $48 \mathrm{~h}$ ) } \\
\hline a. Sora $(0.25-10 \mu \mathrm{M})$ & $\mathrm{IC}_{70}=5.71$ & N.D & N.A & $\mathrm{IC}_{50}=5.43$ & N.A & N.A \\
\hline b. Sora $(0.25-10 \mu \mathrm{M})+\operatorname{Cur}(60 \mu \mathrm{M})$ & $\mathrm{IC}_{70}=0.29$ & 19.70 & 0.0060 & $\mathrm{IC}_{50}=4.25$ & 1.27 & 0.3160 \\
\hline c. Sora $(0.25-10 \mu \mathrm{M})+\operatorname{Cur}(120 \mu \mathrm{M})$ & $\mathrm{IC}_{70}=0.29$ & 19.70 & 0.0030 & $\mathrm{IC}_{50}=1.40$ & 3.88 & 0.2250 \\
\hline \multicolumn{7}{|c|}{ 2. Inverted sequential treatment with Sora and Cur: Cur ( $24 \mathrm{~h})$ followed by Sora ( $48 \mathrm{~h})$} \\
\hline a. Sora $(0.25-10 \mu \mathrm{M})$ & $\mathrm{IC}_{50}=4.86$ & N.A & N.A & 4.44 & N.A & $\begin{array}{l}0.0040 \text { vs. } \mathrm{b} \\
0.0410 \text { vs. c }\end{array}$ \\
\hline b. Sora $(0.25-10 \mu \mathrm{M})+\operatorname{Cur}(60 \mu \mathrm{M})$ & $\mathrm{IC}_{50}=3.14$ & 1.55 & 0.3580 & N.D & N.D & $\mathrm{b}$ \\
\hline c. Sora $(0.25-10 \mu \mathrm{M})+\operatorname{Cur}(120 \mu \mathrm{M})$ & $\mathrm{IC}_{50}=0.29$ & 16.76 & 0.1060 & 9.33 & 0.48 & $\mathrm{c}$ \\
\hline \multicolumn{7}{|c|}{ 3. Simultaneous treatment with Sora and Cur (72 h) } \\
\hline a. Sora $(0.25-10 \mu \mathrm{M})(72 \mathrm{~h})$ & $\mathrm{IC}_{90}=8.00$ & N.A & N.A & $\mathrm{IC}_{80}=5.71$ & N.A & N.A \\
\hline b. Sora $(0.25-10 \mu \mathrm{M})+\operatorname{Cur}(60 \mu \mathrm{M})$ & $\mathrm{IC}_{90}=4.00$ & 2.00 & 0.0001 & $\mathrm{IC}_{80}=6.00$ & 0.95 & 0.0710 \\
\hline c. Sora $(0.25-10 \mu \mathrm{M})+\operatorname{Cur}(120 \mu \mathrm{M})$ & $\mathrm{IC}_{90}=0.29$ & 27.59 & 0.0001 & $\mathrm{IC}_{80}=0.57$ & 10.00 & 0.0020 \\
\hline $\begin{array}{l}\text { Single and combined treatment } \\
\text { with Sora and } \mathrm{Kmf}\end{array}$ & $\begin{array}{l}\mathrm{IC}_{50,60, \text { etc. }} \\
\quad(\mu \mathrm{M})\end{array}$ & SR & P-value & $\begin{array}{l}\mathrm{IC}_{50,60, \text { etc. }} \\
\quad(\mu \mathrm{M})\end{array}$ & SR & P-value \\
\hline \multicolumn{7}{|c|}{ 1. Sequential treatment with Sora and Kmf: Sora ( $24 \mathrm{~h})$ followed by Kmf ( $48 \mathrm{~h}$ ) } \\
\hline a. Sora $(0.25-10 \mu \mathrm{M})$ & $\mathrm{IC}_{50}=4.67$ & N.A & N.A & $\mathrm{IC}_{50}=4.22$ & N.A & $\begin{array}{l}0.1240 \text { vs. b } \\
0.2920 \text { vs. c }\end{array}$ \\
\hline b. Sora $(0.25-10 \mu \mathrm{M})+\operatorname{Kmf}(60 \mu \mathrm{M})$ & $\mathrm{IC}_{50}=5.11$ & 0.91 & 0.8690 & $\mathrm{IC}_{50}=7.56$ & 0.56 & $\mathrm{~b}$ \\
\hline c. Sora $(0.25-10 \mu \mathrm{M})+\mathrm{Kmf}(120 \mu \mathrm{M})$ & $\mathrm{IC}_{50}=4.00$ & 1.17 & 0.4000 & $\mathrm{IC}_{50}=5.11$ & 0.83 & $\mathrm{c}$ \\
\hline \multicolumn{7}{|c|}{ 2. Inverted sequential treatment with Sora and $\mathrm{Kmf}$ : Kmf ( $24 \mathrm{~h})$ followed by Sora ( $48 \mathrm{~h})$} \\
\hline a. Sora $(0.25-10 \mu \mathrm{M})$ & $\mathrm{IC}_{60}=5.11$ & N.A & N.A & $\mathrm{IC}_{50}=4.44$ & N.A & $\begin{array}{l}0.0240 \text { vs. b } \\
0.8660 \text { vs. c }\end{array}$ \\
\hline b. Sora $(0.25-10 \mu \mathrm{M})+\operatorname{Kmf}(60 \mu \mathrm{M})$ & $\mathrm{IC}_{60}=3.56$ & 1.44 & 0.1810 & N.D & N.D & $\mathrm{b}$ \\
\hline c. Sora $(0.25-10 \mu \mathrm{M})+\mathrm{Kmf}(120 \mu \mathrm{M})$ & $\mathrm{IC}_{60}=2.44$ & 2.10 & 0.0400 & 5.33 & 0.83 & $\mathrm{c}$ \\
\hline \multicolumn{7}{|c|}{ 3. Simultaneous treatment with Sora and $\mathrm{Kmf}(72 \mathrm{~h})$} \\
\hline a. Sora $(0.25-10 \mu \mathrm{M})$ & $\mathrm{IC}_{50}=4.86$ & N.A & N.A & $\mathrm{IC}_{50}=4.44$ & N.A & N.A \\
\hline b. Sora $(0.25-10 \mu \mathrm{M})+\operatorname{Kmf}(60 \mu \mathrm{M})$ & $\mathrm{IC}_{50}=1.43$ & 3.39 & 0.0570 & $\mathrm{IC}_{50}=1.56$ & 2.85 & 0.2280 \\
\hline c. Sora $(0.25-10 \mu \mathrm{M})+\mathrm{Kmf}(120 \mu \mathrm{M})$ & $\mathrm{IC}_{50}=0.29$ & 16.76 & 0.0240 & $\mathrm{IC}_{50}=1.56$ & 2.85 & 0.2580 \\
\hline
\end{tabular}

SR, sensitization ratio; The ratio between $\mathrm{IC}_{50,60 \text {, etc. }}$ of Sora and $\mathrm{IC}_{50,60, \text { etc. }}$, of Sora plus NPC. N.A, not applicable; N.D, not determined; NPC, natural phenolic compound.

and slightly increased the cell population in the $\mathrm{G}_{2} / \mathrm{M}$-phase $(\mathrm{P}=0.389)$ compared to cells treated with Cur $(400 \mu \mathrm{M})$. On the other hand, cells treated with Cur $(400 \mu \mathrm{M})$ demonstrated a significant increase in the number of cells in S-phase $(\mathrm{P}=0.0001)$ compared to the combined treatment (Fig. 6A).

Treatment of HepG2 cells with Sora $(5 \mu \mathrm{M})$ resulted in an increase in the $\mathrm{G}_{0} / \mathrm{G}_{1}$-phase population $(\mathrm{P}=0.054)$, accompanied with a significant decrease in the population of cells in the S-phase $(\mathrm{P}=0.025)$ and the $\mathrm{G}_{2} / \mathrm{M}$-phase $(\mathrm{P}=0.79)$ compared to UT. Sora only slightly increased the amount of apoptosis in HepG2 cells (\% subG1 $=0.69$ vs. $0.02 \%$ for UT; Fig. 6B). By contrast, Cur $(200 \mu \mathrm{M})$ inhibited the growth of HepG2 cells by increasing the population in the $\mathrm{S}$-phase $(\mathrm{P}=0.038)$ and the $\mathrm{G}_{2} / \mathrm{M}$-phase $(\mathrm{P}=0.728)$ with a corresponding decrease in the population of cells in $\mathrm{G}_{0} / \mathrm{G}_{1}$-phase $(\mathrm{P}=0.004)$ compared to UT. Cur $(200 \mu \mathrm{M})$ also only induced apoptosis in HepG2 cells to a minimal extent ( $\%$ subG1 $=0.75$ vs. $0.02 \%$ for UT; Fig. $6 B$ ). Furthermore, Cur $(400 \mu \mathrm{M})$ markedly inhibited the growth of HepG2 cells by increasing the population in $\mathrm{G}_{2} / \mathrm{M}$ phase $(\mathrm{P}=0.0001)$ with a corresponding decrease in the number of cells in the $\mathrm{G}_{0} / \mathrm{G}_{1}$-phase $(\mathrm{P}=0.0001)$ and the $\mathrm{S}$-phase $(\mathrm{P}=0.473)$. Cur $(400 \mu \mathrm{M})$ induced apoptosis in HepG2 cells (\% subG1=5.0 vs. 0.02 for UT; Fig. 6B).

Simultaneous combined treatment with Sora $(5 \mu \mathrm{M})$ and Cur $(200 \mu \mathrm{M})$ greatly inhibited the growth of HepG2 cells by increasing the population in the $\mathrm{S}$-phase $(\mathrm{P}=0.0001)$ but only slightly in the $G_{2} / M$-phase $(P=0.468)$ with a corresponding decrease in the cell population in $\mathrm{G}_{0} / \mathrm{G}_{1}$-phase $(\mathrm{P}=0.0001)$ 


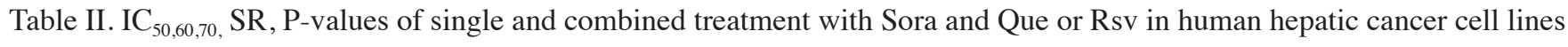

\begin{tabular}{|c|c|c|c|c|c|c|}
\hline \multirow[b]{2}{*}{ Single and combined treatment with Sora and Cur } & \multicolumn{3}{|c|}{ Hep3b } & \multicolumn{3}{|c|}{ HepG2 } \\
\hline & $\mathrm{IC}_{50,60, \text { etc }} \cdot(\mu \mathrm{M})$ & $\mathrm{SR}$ & $\mathrm{P}$-value & $\mathrm{IC}_{50,60, \text { etc. }}(\mu \mathrm{M})$ & $\mathrm{SR}$ & P-value \\
\hline
\end{tabular}

1. Sequential treatment with Sora and Que:

Sora ( $24 \mathrm{~h})$ followed by Que (48 h)
a. Sora $(0.25-10 \mu \mathrm{M})$
b. Sora $(0.25-10 \mu \mathrm{M})+$ Que $(60 \mu \mathrm{M})$
$\mathrm{IC}_{50}=4.86$

N.A
N.A
$\mathrm{IC}_{50}=4.29$
N.A
N.A
c. Sora $(0.25-10 \mu \mathrm{M})+$ Que $(120 \mu \mathrm{M})$

$\mathrm{IC}_{50}=4.00 \quad 1.21 \quad 0.9350$
$\mathrm{IC}_{50}=3.71 \quad 1.16$
0.5660
$\mathrm{IC}_{50}=4.00 \quad 1.21 \quad 0.5830$
$\mathrm{IC}_{50}=3.71 \quad 1.16$
0.7110

2. Inverted sequential treatment with Sora and Que: Que (24 h) followed by Sora (48 h)
a. Sora $(0.25-10 \mu \mathrm{M})$
$\mathrm{IC}_{60}=4.86$
N.A
N.A
$\mathrm{IC}_{50}=4.44$
N.A
0.0200 vs. b
b. Sora $(0.25-10 \mu \mathrm{M})+$ Que $(60 \mu \mathrm{M})$
$\mathrm{IC}_{60}=3.43$
1.42
0.1930
N.D 0.7290 vs. c
c. Sora $(0.25-10 \mu \mathrm{M})+$ Que $(120 \mu \mathrm{M})$
$\mathrm{IC}_{60}=0.58 \quad 8.38 \quad 0.0130$
N.D
N.D b
$0.63 \quad \mathrm{c}$

3. Simultaneous treatment with Sora and Que (72 h)
a. Sora $(0.25-10 \mu \mathrm{M})(72 \mathrm{~h})$
$\mathrm{IC}_{50}=4.58 \quad$ N.A
N.A
$\mathrm{IC}_{50}=4.44$
N.A 0.8880 vs. b
b. Sora $(0.25-10 \mu \mathrm{M})+$ Que $(60 \mu \mathrm{M})$
$\mathrm{IC}_{50}=1.14 \quad 4.02$
0.0680
$\mathrm{IC}_{50}=3.78$
1.18
b
c. Sora $(0.25-10 \mu \mathrm{M})+$ Que $(120 \mu \mathrm{M})$
$\mathrm{IC}_{50}=0.58 \quad 7.90 \quad 0.0620$
$\mathrm{IC}_{50}=3.11$
1.43
0.7090

Single and combined treatment with Sora and Rsv $\quad \mathrm{IC}_{50,60, \text { etc. }}(\mu \mathrm{M}) \quad \mathrm{SR} \quad \mathrm{P}$-value $\quad \mathrm{IC}_{50,60, \text { etc. }}(\mu \mathrm{M}) \quad \mathrm{SR} \quad \mathrm{P}$-value

1. Sequential treatment with Sora and Rsv:

Sora (24 h) followed by Rsv (48 h)
a. Sora $(0.25-10 \mu \mathrm{M})$
$\mathrm{IC}_{50}=4.67$
N.A
0.712 vs. b
$\mathrm{IC}_{50}=4.44$
N.A
0.1050 vs. $b$
b. Sora $(0.25-10 \mu \mathrm{M})+\operatorname{Rsv}(40 \mu \mathrm{M})$
$\mathrm{IC}_{50}=5.33$
0.88
b
$\mathrm{IC}_{50}=5.11$
0.91
0.8450

N.D
N.D
0.6080 vs. c
c. Sora $(0.25-10 \mu \mathrm{M})+\operatorname{Rsv}(80 \mu \mathrm{M})$

2. Inverted sequential treatment with Sora and Rsv: Rsv (24 h) followed by Sora (48 h)
a. Sora $(0.25-10 \mu \mathrm{M})$
b. Sora $(0.25-10 \mu \mathrm{M})+\operatorname{Rsv}(40 \mu \mathrm{M})$
c. Sora $(0.25-10 \mu \mathrm{M})+\operatorname{Rsv}(80 \mu \mathrm{M})$

$\mathrm{IC}_{70}=5.60$

N.A

N.A

$\mathrm{IC}_{50}=4.44$

N.A

0.0220 vs. b

$\mathrm{IC}_{70}=1.11$

$5.10 \quad 0.0010$

N.D
0.0330 vs. c

N.D

N.D $\quad 0.0001$

$\mathrm{IC}_{50}=9.80$

N.D

b

$\begin{array}{lcc}\mathrm{IC}_{50}=4.67 & \text { N.A } & \text { N.A } \\ \mathrm{IC}_{50}=1.33 & 3.51 & 0.0660 \\ \mathrm{IC}_{50}=0.44 & 10.60 & 0.0300\end{array}$

$\begin{array}{ll}\mathrm{IC}_{50}=4.44 & \text { N.A } \\ \mathrm{IC}_{50}=3.56 & 1.25 \\ \mathrm{IC}_{50}=3.56 & 1.25\end{array}$

N.A

0.9720

0.5930

SR, sensitization ratio; The ratio between $\mathrm{IC}_{50,60 \text {, etc. }}$, of Sora and $\mathrm{IC}_{50,60 \text {, etc. }}$, of Sora plus NPC. N.A, Not applicable; N.D, Not determined; ; NPC, natural phenolic compound.

compared to UT. This combination induced a small amount of apoptosis in HepG2 cells (\% subG1=0.25 vs. $0.02 \%$ for UT; Fig. 6B). In addition, simultaneous combined treatment with Sora $(5 \mu \mathrm{M})$ and Cur $(400 \mu \mathrm{M})$ greatly inhibited the growth of HepG2 cells by increasing the $\mathrm{S}$-phase population $(\mathrm{P}=0.0001)$ with a concomitant decrease in cell populations in the G0/G1-phase $(\mathrm{P}=0.0001)$ and the $\mathrm{G}_{2} / \mathrm{M}$-phase $(\mathrm{P}=0.176)$ compared to UT. This combination induced a small amount of apoptosis in HepG2 cells (\% subG1=0.974 vs. $0.02 \%$ for UT; Fig. 6B).

Simultaneous combined treatment of HepG2 cells with Sora $(5 \mu \mathrm{M})$ and Cur $(200 \mu \mathrm{M})$ significantly increased the number of cells in S-phase compared to single treatment with $5 \mu \mathrm{M}$ Sora $(\mathrm{P}=0.0001)$ and $200 \mu \mathrm{M}$ Cur $(\mathrm{P}=0.005)$. Also, this combination slightly increased the cell population in $\mathrm{G}_{2} / \mathrm{M}$-phase compared to single treatment with Sora $(\mathrm{P}=0.242)$ and Cur $(\mathrm{P}=0.42)$. On the other hand, single treatment of HepG2 cells with Sora and Cur significantly increased the cell population in $\mathrm{G}_{0} / \mathrm{G}_{1}$-phase $(\mathrm{P}=0.0001)$ compared to the combined treatment (Fig. 6B).

Simultaneous combined treatment of HepG2 cells with Sora $(5 \mu \mathrm{M})$ and Cur $(400 \mu \mathrm{M})$ significantly increased the number of cells in both the $\mathrm{S}$-phase $(\mathrm{P}=0.0001)$ and 

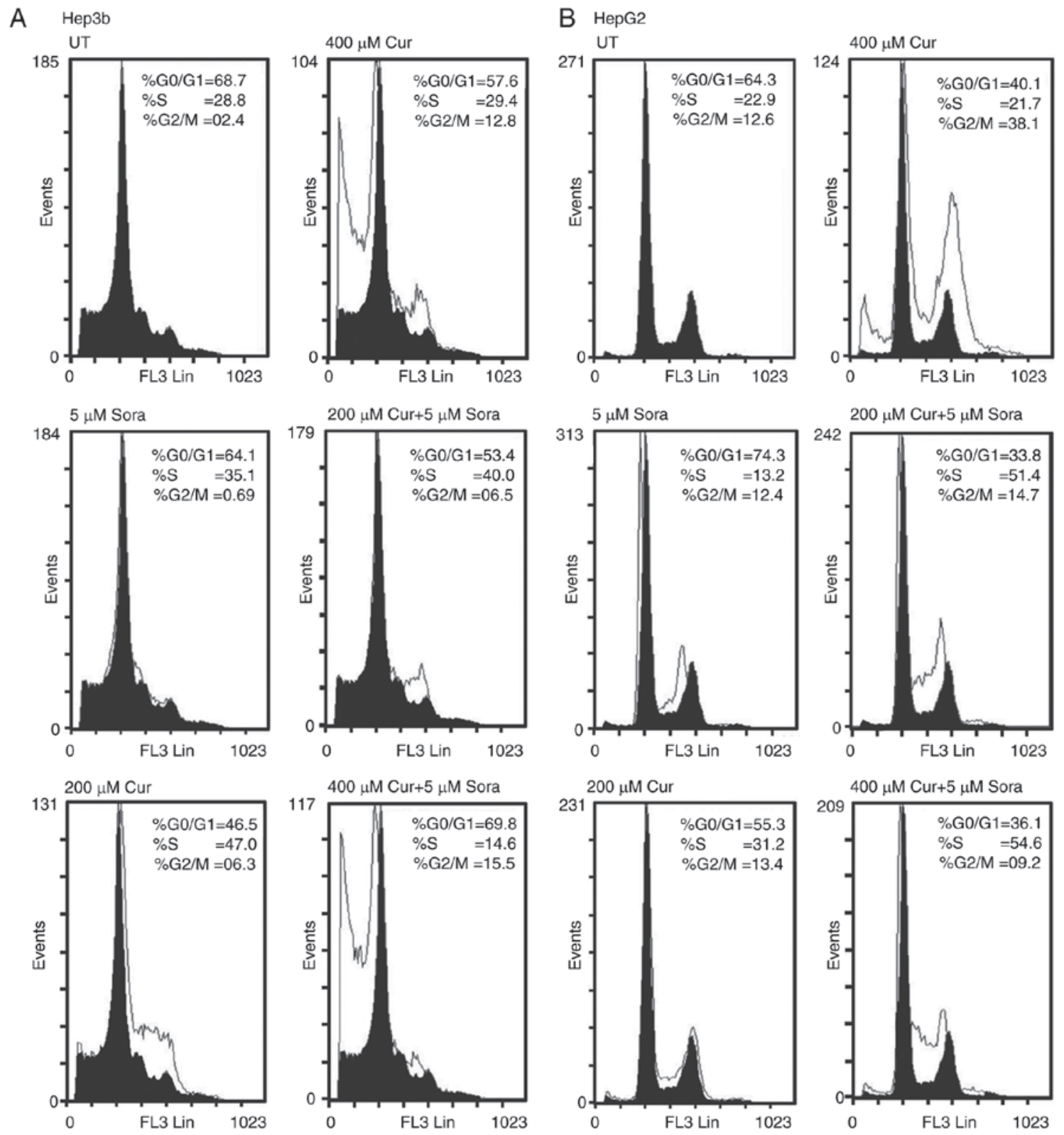

Figure 6. Analysis of cell cycle perturbation in human cancer cell lines treated with Sora, Cur and their simultaneous combination. (A) Hep3b and (B) HepG2 hepatic cancer cell lines were either left untreated or treated with Sora $(5 \mu \mathrm{M})$, Cur $(200 \mu \mathrm{M})$, Cur $(400 \mu \mathrm{M})$, or simultaneous combinations of Sora and Cur $(5 \mu \mathrm{M}+200 \mu \mathrm{M})$ or $(5 \mu \mathrm{M}+400 \mu \mathrm{M})$ for $72 \mathrm{~h}$. At least three samples were analyzed and 20,000 events were scored for each sample. The vertical axis represents the relative number of events and the horizontal axis represents the fluorescence intensity. Sora, sorafenib; Cur, curcumin; UT, untreated. The black and white curves are for control and experimental groups, respectively.

$\mathrm{G}_{0} / \mathrm{G}_{1}$-phase $(\mathrm{P}=0.0001)$ compared to single treatment with Sora $(5 \mu \mathrm{M})$ and Cur $(400 \mu \mathrm{M})$. In addition, treatment of HepG2 with Sora $(5 \mu \mathrm{M})$ slightly increased the cell population in $\mathrm{G}_{2} / \mathrm{M}$-phase $(\mathrm{P}=0.174)$. Furthermore, HepG2 cells-treated with Cur $(400 \mu \mathrm{M})$ were significantly arrested in $\mathrm{G}_{2} / \mathrm{M}$-phase $(\mathrm{P}=0.0001)$ compared to the combined treatment (Fig. 6B).

Single and combined treatment with Sora and Kmf. Treatment of Hep3b cells with Sora $(5 \mu \mathrm{M})$ inhibited their growth by increasing the population in the $\mathrm{S}$-phase $(\mathrm{P}=0.151)$ with a corresponding decrease in the percentage of cells in the $\mathrm{G}_{0} / \mathrm{G}_{1}$-phase $(\mathrm{P}=0.145)$ and the $\mathrm{G}_{2} / \mathrm{M}$-phase $(\mathrm{P}=0.001)$ compared to UT (Fig. 7A). Treatment with $\mathrm{Kmf}(200 \mu \mathrm{M})$ resulted in a marked inhibition of Hep $3 b$ cell growth by increasing the $\mathrm{S}$-phase population $(\mathrm{P}=0.151)$ and the
$\mathrm{G}_{2} / \mathrm{M}$-phase population ( $\left.\mathrm{P}=0.0001\right)$ with a corresponding decrease in the number of cells in the $G_{0} / G_{1}$-phase $(p=0.0001)$ compared to UT. Kmf $(200 \mu \mathrm{M})$ markedly induced apoptosis in Hep3b cells (\% subG1=21.8 vs. $6.7 \%$ for UT; Fig. 7A). Furthermore, $\mathrm{Kmf}(400 \mu \mathrm{M})$ inhibited the growth of cancer cells by increasing the population in the S-phase $(P=0.003)$ and $G_{2} / M-p h a s e(P=0.001)$ with a concomitant decrease in the number of cells in the $G_{0} / G_{1}$-phase $(P=0.002)$ compared to UT. Kmf (400 $\mu \mathrm{M})$ slightly induced apoptosis in Hep3b cells (7.8 vs. $6.7 \%$ for UT; Fig. 7A). Simultaneous combined treatment with Sora $(5 \mu \mathrm{M})$ and $\mathrm{Kmf}(200 \mu \mathrm{M})$ also markedly increased the population of Hep3b cells in the S-phase $(\mathrm{P}=0.214)$ and the $\mathrm{G}_{2} / \mathrm{M}$-phase $(\mathrm{P}=0.0001)$ with a corresponding reduction in the percentage of cells in the $\mathrm{G}_{0} / \mathrm{G}_{1}$-phase $(\mathrm{P}=0.0001)$ compared to UT. This combined 

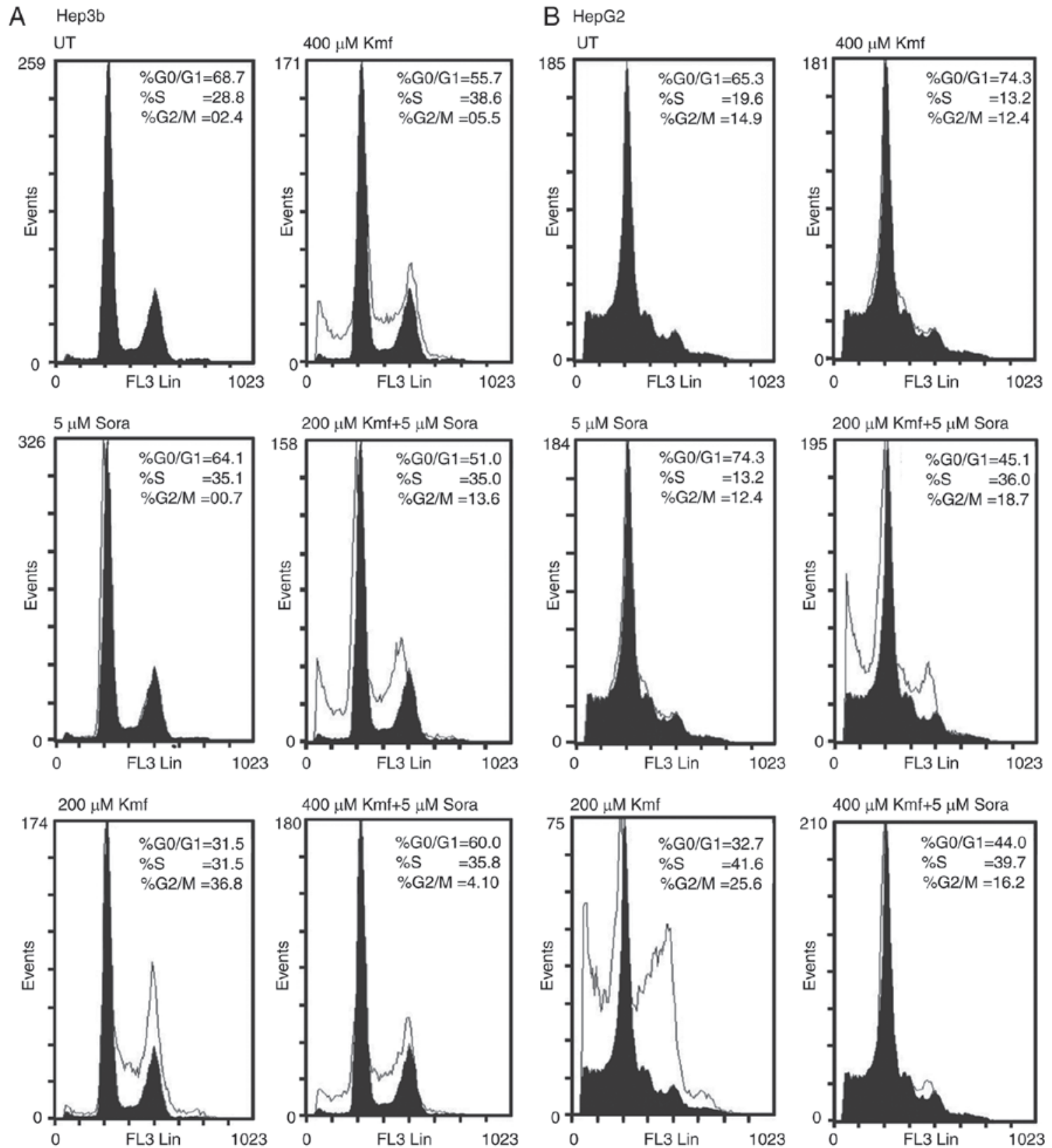

Figure 7. Analysis of cell cycle perturbation in human cancer cell lines treated with Sora, Kmf and their simultaneous combination. (A) Hep3b and (B) HepG2 hepatic cancer cell lines were either left untreated or treated with Sora $(5 \mu \mathrm{M}), \operatorname{Kmf}(200 \mu \mathrm{M}), \operatorname{Kmf}(400 \mu \mathrm{M})$, or simultaneous combinations of Sora and $\mathrm{Kmf}$ $(5 \mu \mathrm{M}+200 \mu \mathrm{M})$ or $(5 \mu \mathrm{M}+400 \mu \mathrm{M})$ for $72 \mathrm{~h}$. At least three samples were analyzed and 20,000 events were scored for each sample. The vertical axis represents the relative number of events and the horizontal axis represents the fluorescence intensity. The black and white curves are for control and experimental groups, respectively. Sora, sorafenib; Kmf, kaempferol; UT, untreated.

treatment markedly induced apoptosis in Hep3b cells $(\%$ subG1 $=23.2$ vs. $6.7 \%$ for UT; Fig. 7A). In addition, simultaneous combined treatment with Sora $(5 \mu \mathrm{M})$ and $\mathrm{Kmf}$ $(400 \mu \mathrm{M})$ inhibited the growth of Hep3b cells by increasing the population in the $\mathrm{S}$-phase $(\mathrm{P}=0.186)$ and $\mathrm{G}_{2} / \mathrm{M}$-phase $(\mathrm{P}=0.231)$ with a concomitant decrease in the population of cells in the $\mathrm{G}_{0} / \mathrm{G}_{1}$ phase $(\mathrm{P}=0.013)$ compared to UT (Fig. 7A).

Simultaneous combined treatment of Hep3b with Sora $(5 \mu \mathrm{M})$ and $\mathrm{Kmf}(200 \mu \mathrm{M})$ significantly increased the number of cells in the $\mathrm{G}_{2} / \mathrm{M}$-phase $(\mathrm{P}=0.0001)$ with a corresponding decrease in the cell population in $\mathrm{G}_{0} / \mathrm{G}_{1}$-phase $(\mathrm{P}=0.002)$ and no alteration in cell population in S-phase compared with the single treatment with Sora $(5 \mu \mathrm{M}$; Fig. 7A). On the other hand, this combination caused a significant increase in the number of cells in the $\mathrm{G}_{0} / \mathrm{G}_{1}$-phase $(\mathrm{P}=0.0001)$ and a slight increase in cell population in $\mathrm{S}$-phase $(\mathrm{P}=0.224)$ with corresponding decrease in the cell number in $\mathrm{G}_{2} / \mathrm{M}$-phase $(\mathrm{P}=0.0001)$ compared to single treatment with $\mathrm{Kmf}(200 \mu \mathrm{M}$; Fig. 7A).

Simultaneous combined treatment of Hep3b with Sora $(5 \mu \mathrm{M})$ and $\mathrm{Kmf}(400 \mu \mathrm{M})$ significantly increased the number of cells in $\mathrm{G}_{2} / \mathrm{M}$-phase $(\mathrm{P}=0.001)$ and S-phase $(\mathrm{P}=0.697)$ with corresponding decrease in the number of cells in $\mathrm{G}_{0} / \mathrm{G}_{1}$-phase $(\mathrm{P}=0.134)$ compared to single treatment with Sora $(5 \mu \mathrm{M}$; Fig. 7A). Furthermore, this combination increased the cell population in $\mathrm{G}_{0} / \mathrm{G}_{1}$-phase $(\mathrm{P}=0.134)$ with concomitant decrease in the number of cells in both $\mathrm{G}_{2} / \mathrm{M}$-phase $(\mathrm{P}=0.047)$ and $\mathrm{S}$-phase $(\mathrm{P}=0.267)$ compared to single treatment with $\operatorname{Kmf}(400 \mu \mathrm{M}$; Fig. 7A). 

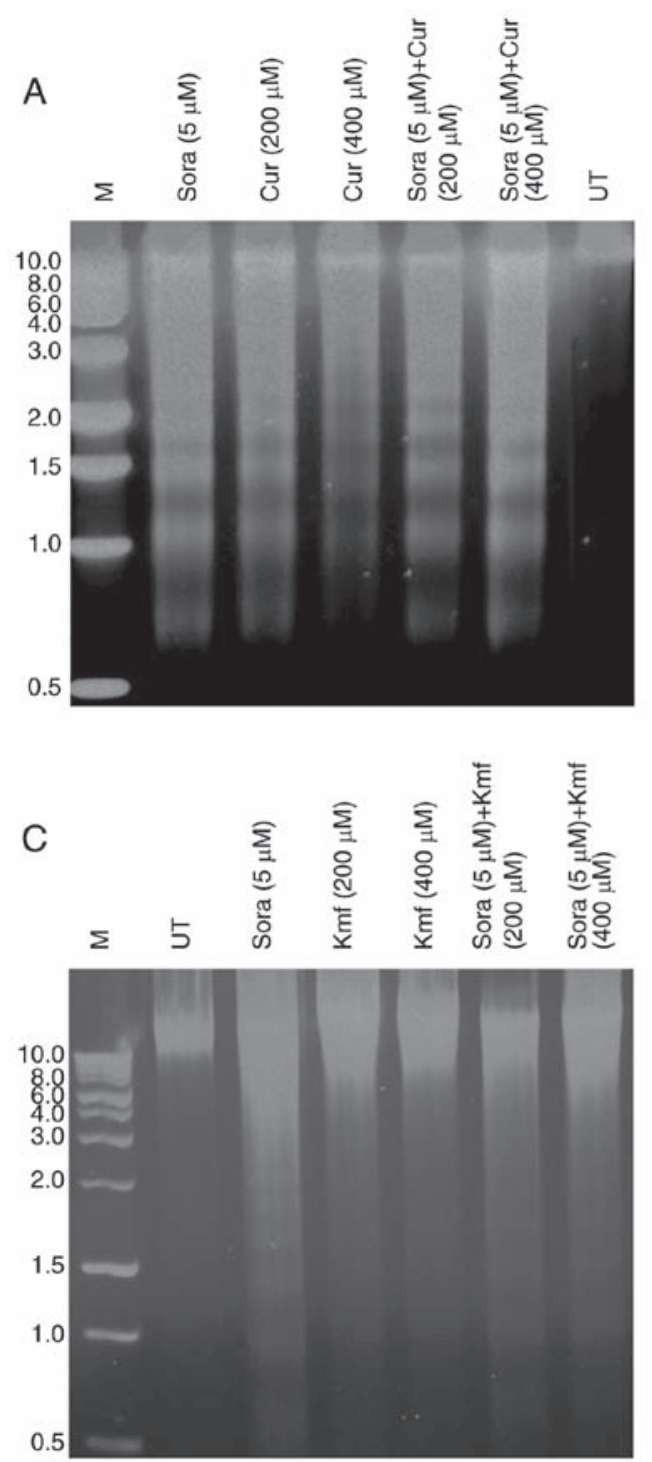
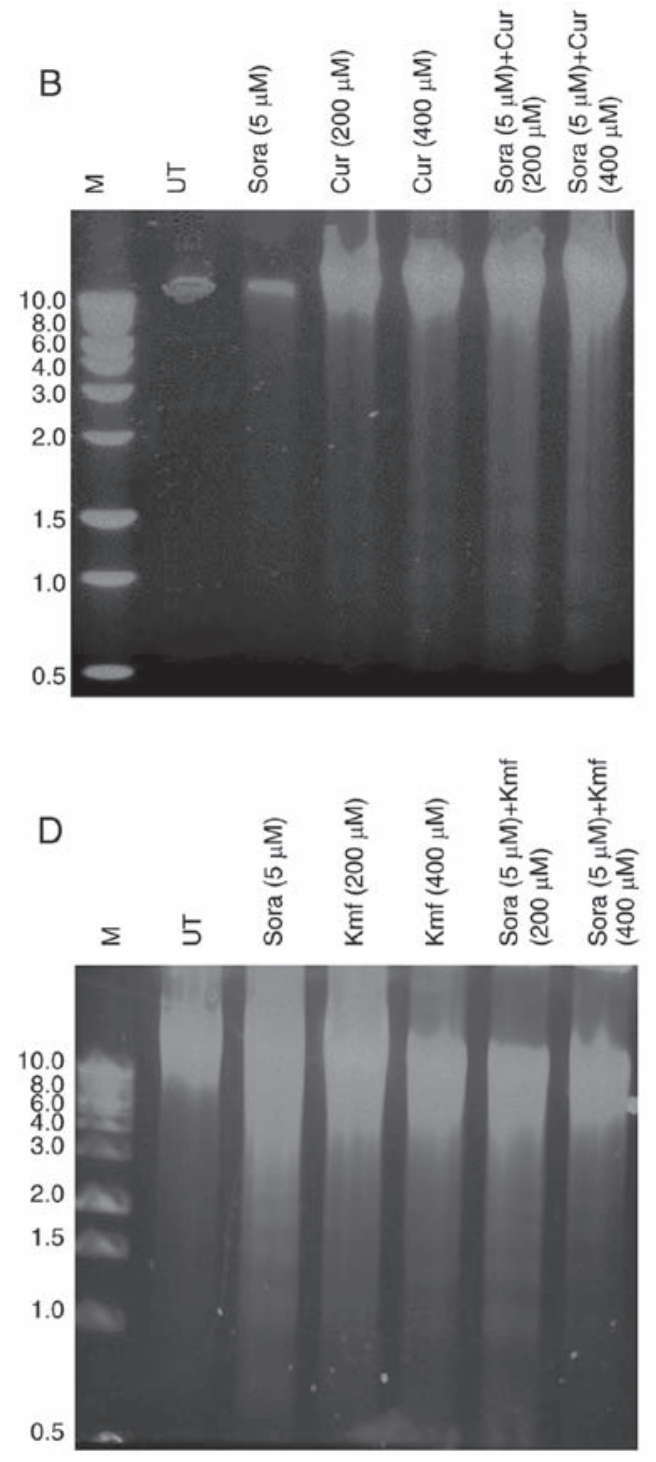

Figure 8. Analysis of DNA fragmentation in human hepatic cancer cell lines treated with Sora, Cur, Kmf and their simultaneous combinations. (A and B) Hep3b and HepG2 hepatic cancer cell lines treated with Sora $(5 \mu \mathrm{M})$, Cur (200 or $400 \mu \mathrm{M})$, or their simultaneous combinations or (C and D) Sora (5 $\mu \mathrm{M})$, Kmf $(200$ or $400 \mu \mathrm{M}$ ) and their simultaneous combinations for $48 \mathrm{~h}$. DNA fragments were extracted and analyzed on 1\% agarose. M, 1,000 bp DNA marker. Sora, sorafenib; Kmf, kaempferol; UT, untreated; Cur, curcumin.

Treatment of HepG2 cells with Sora $(5 \mu \mathrm{M})$ inhibited their growth by increasing the population of cells in $\mathrm{G}_{0} / \mathrm{G}_{1}$-phase $(\mathrm{P}=0.005)$ with a corresponding decrease in the number of cells in S-phase $(\mathrm{P}=0.004)$ and $\mathrm{G}_{2} / \mathrm{M}$-phase $(\mathrm{P}=0.876)$ compared to UT (Fig. 7B). Treatment of HepG2 cells with $\mathrm{Kmf}(200 \mu \mathrm{M})$ resulted in a marked inhibition of cell growth by increasing the population in the $\mathrm{S}$-phase $(\mathrm{P}=0.0001)$ and $\mathrm{G}_{2} / \mathrm{M}$-phase $(\mathrm{P}=0.0001)$ with a corresponding decrease in the number of cells in the $\mathrm{G}_{0} / \mathrm{G}_{1}$-phase $(\mathrm{P}=0.0001)$ compared to UT. Kmf $(200 \mu \mathrm{M})$ induced a small amount of apoptosis in HepG 2 cells (\% subG1 $=0.63$ vs. $0.02 \%$ for UT) (Fig. 7B). In addition, $\mathrm{Kmf}(400 \mu \mathrm{M})$ clearly inhibited the growth of cancer cells by increasing the population in $\mathrm{S}$-phase $(\mathrm{P}=0.0001)$ and $\mathrm{G}_{2} / \mathrm{M}$-phase $(\mathrm{P}=0.116)$ with a concomitant decrease in the number of cells in the $\mathrm{G}_{0} / \mathrm{G}_{1}$ phase $(\mathrm{P}=0.001)$ compared to $\mathrm{UT}$. $\mathrm{Kmf}(400 \mu \mathrm{M})$ evidently induced apoptosis in HepG2 cells (\% subG1 $=6.20$ vs. $0.02 \%$; Fig. 7B). Simultaneous combined treatment with Sora $(5 \mu \mathrm{M})$ and $\mathrm{Kmf}(200 \mu \mathrm{M})$ also increased the population of HepG2 cells in the S-phase $(\mathrm{P}=0.0001)$ and
$\mathrm{G}_{2} / \mathrm{M}$-phase $(\mathrm{P}=0.05)$ with a corresponding reduction in the percentage of cells in the $G_{0} / G_{1}$ phase $(P=0.0001)$ compared to UT. This combined treatment induced apoptosis in HepG2 cells (\% subG1 $=8.4$ vs. $0.02 \%$ for UT; Fig. 7B). Furthermore, simultaneous combined treatment with Sora $(5 \mu \mathrm{M})$ and $\mathrm{Kmf}$ $(400 \mu \mathrm{M})$ increased the population of HepG2 cells in S-phase $(\mathrm{P}=0.0001)$ and $\mathrm{G}_{2} / \mathrm{M}$-phase $(\mathrm{P}=0.563)$ with corresponding decrease in the number of cells in $\mathrm{G} 0 / \mathrm{G} 1$-phase $(\mathrm{P}=0.0001)$ compared to UT. This combination also induced apoptosis in HepG2 cells (\% subG1 $=3.3$ vs. $0.02 \%$ for UT; Fig. 7B).

Simultaneous combined treatment of HepG2 with Sora $(5 \mu \mathrm{M})$ and $\mathrm{Kmf}(200 \mu \mathrm{M})$ significantly increased the number of cells in both the $\mathrm{S}$-phase $(\mathrm{P}=0.0001)$ and $\mathrm{G}_{2} / \mathrm{M}$-phase $(\mathrm{P}=0.013)$ with corresponding significant decrease in the cell number in $\mathrm{G}_{0} / \mathrm{G}_{1}$-phase $(\mathrm{P}=0.0001)$ compared to single treatment with Sora (5 $\mu \mathrm{M}$; Fig. 7B). Furthermore, this combination significantly increased the accumulation of HepG2 cells in $\mathrm{G}_{0} / \mathrm{G}_{1}$-phase $(\mathrm{P}=0.002)$ with corresponding decrease in the number of cells in both $\mathrm{S}$-phase $(\mathrm{P}=0.01)$ and $\mathrm{G}_{2} / \mathrm{M}$-phase $(\mathrm{P}=0.02)$ compared 
A Hep3b

a UT

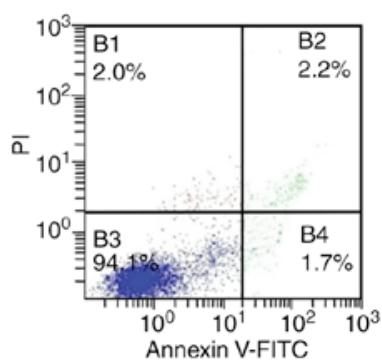

b $5 \mu \mathrm{M}$ Sora

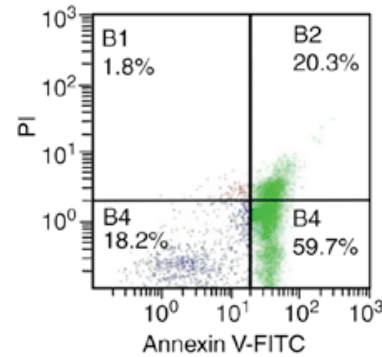

C $200 \mu \mathrm{M}$ Cur

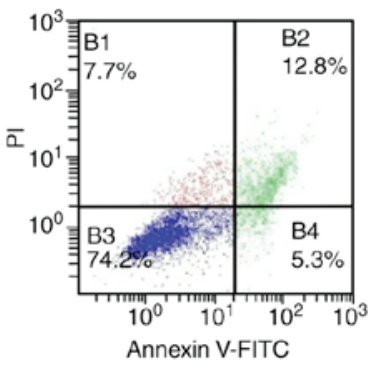

d $400 \mu \mathrm{M}$ Cur

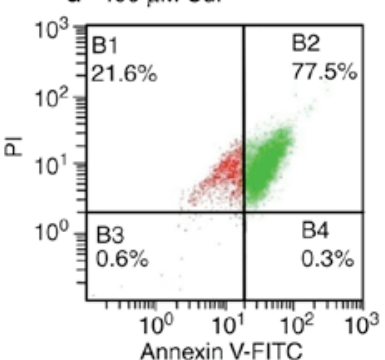

e $200 \mu \mathrm{M}$ Cur+5 $\mu \mathrm{M}$ Sora

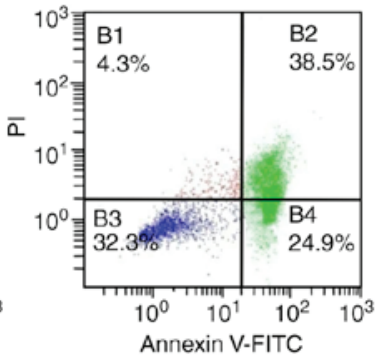

f $400 \mu \mathrm{M}$ Cur $+5 \mu \mathrm{M}$ Sora

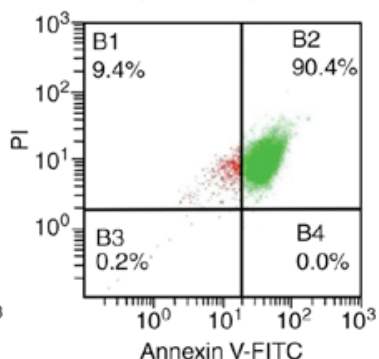

B HepG2

a UT
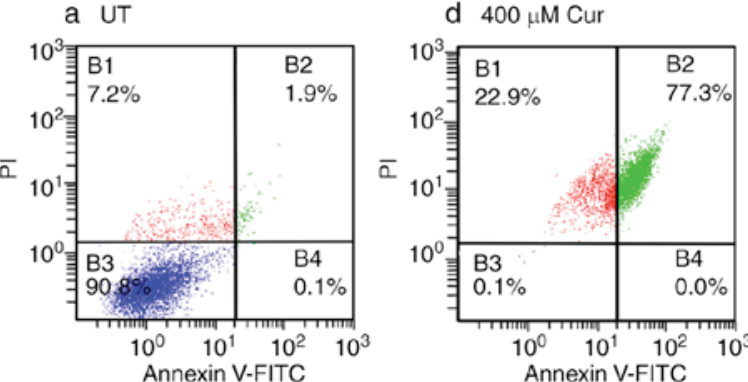

b $5 \mu \mathrm{M}$ Sora

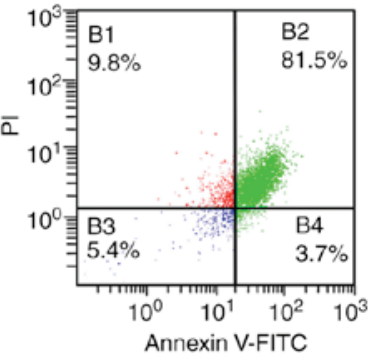

e $200 \mu \mathrm{M}$ Cur $+5 \mu \mathrm{M}$ Sora

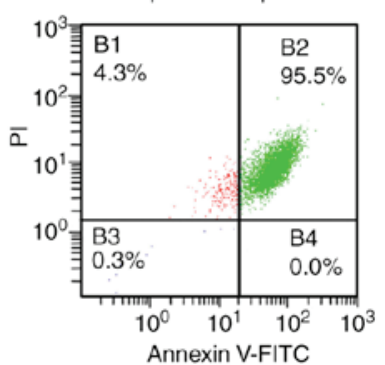

f $400 \mu \mathrm{M}$ Cur $+5 \mu \mathrm{M}$ Sora
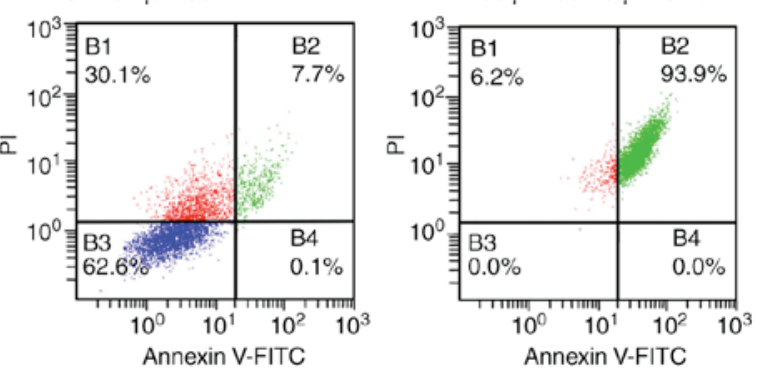

Figure 9. Flow cytometric analysis of apoptosis of human hepatic cancer cell lines treated with Sora, Cur and their simultaneous combinations. (A) Hep3b and (B) HepG2 hepatic cancer cell lines were (a) left untreated or treated with (b) Sora (5 $\mu \mathrm{M})$, (c) Cur (200 $\mu \mathrm{M})$, (d) Cur (400 $\mu \mathrm{M})$, or (e and f) simultaneous combinations of Sora and $\operatorname{Cur}(5 \mu \mathrm{M}+200 \mu \mathrm{M}$, respectively) or $(5 \mu \mathrm{M}+400 \mu \mathrm{M}$, respectively) for $48 \mathrm{~h}$. The cells were analyzed by flow cytometry after processing and staining with Annexin V-FITC/PI. B1, percentage of necrotic cells; B2, percentage of late apoptotic cells; B3, percentage of viable cells; and B4, percentage of early apoptotic cells. Sora, sorafenib; Cur, curcumin; UT, untreated; PI, propidium iodide; FITC, fluorescein isothiocyanate.

with the single treatment with $\mathrm{Kmf}(200 \mu \mathrm{M}$; Fig. 7B). Simultaneous combined treatment of HepG2 with Sora $(5 \mu \mathrm{M})$ and $\mathrm{Kmf}(400 \mu \mathrm{M})$ significantly increased the number of cells in both $\mathrm{S}$-phase $(\mathrm{P}=0.0001)$ and $\mathrm{G}_{2} / \mathrm{M}$-phase $(\mathrm{P}=0.05)$ with corresponding decrease in the cell population in $\mathrm{G}_{0} / \mathrm{G}_{1}$-phase $(\mathrm{P}=0.0001)$ compared to single treatment with Sora $(5 \mu \mathrm{M}$; Fig. 7B). Also, this combined treatment significantly increased the accumulation of cells in both $\mathrm{S}$-phase $(\mathrm{P}=0.0001)$ and $\mathrm{G}_{2} / \mathrm{M}$-phase $(\mathrm{P}=0.05)$ with concomitant significant decrease in population of cells in $\mathrm{G}_{0} / \mathrm{G}_{1}$-phase $(\mathrm{P}=0.0001)$ compared to treatment with $\mathrm{Kmf}(400 \mu \mathrm{M}$; Fig. 7B).

Assessment of apoptosis in hepatic cancer cell lines after mono- and simultaneous combined treatment with Sora and Cur or Kmf. DNA fragmentation, one of the hallmarks of apoptosis, is chromosomal DNA fragmentation into 180-200 bp segments in numerous cell types. DNA fragmentation was identified to be dependent on the type and dose of treatment regimen as well as type of hepatic cancer cell line (Fig. 8A-D). Hep3b treated with Sora, Cur alone and combined exhibited increased DNA fragmentation profile compared with HepG2 (Fig. 8A and B). On the other hand, HepG2 treated with Sora, $\mathrm{Kmf}$ alone and combined demonstrated increased DNA fragmentation than that observed in Hepb3 (Fig. 8C and D). Simultaneous combined treatment with Sora and Cur or Kmf demonstrated higher DNA fragmentation patterns than that produced by single treatment with Sora, Cur or Kmf.

Annexin V/PI double staining. In the early stages of apoptosis, phosphatidylserine (PS) translocates from the inner side of the plasma membrane to the outer layer, therefore exposing PS at the external surface of the cell. Annexin- $\mathrm{V}$, a calcium-dependent phospholipid-binding protein, has a high affinity for PS and can be used as a sensitive probe to measure the exposure of this phospholipid on the cell membrane (16). During the initial stages of apoptosis, the cell membrane remains intact. However, during later stages, the cell membrane loses its integrity and becomes leaky. Therefore, the measurement of Annexin-V binding to the cell surface can be performed in conjunction with a dye-exclusion test, to establish the integrity of the cell membrane and determine the stage of apoptosis (16). A common dye for this application is propidium iodide (PI).

UT Hep3b cells displayed low levels of apoptosis, with only $1.7 \%$ of cells in early apoptosis, $2.2 \%$ in late apoptosis and $2.0 \%$ being necrotic (Fig. 9A-a). Sora $(5 \mu \mathrm{M})$ markedly 
induced apoptosis with $59.7 \%$ of cells in early apoptosis, $20.3 \%$ in late apoptosis and $1.8 \%$ being necrotic (Fig. 9A-b). However, Cur $(200 \mu \mathrm{M})$ caused a lower level of apoptosis than Sora, with $5.3 \%$ of cells in early apoptosis, $12.8 \%$ in late apoptosis and $7.7 \%$ being necrotic (Fig. 9A-c). By contrast, Cur $(400 \mu \mathrm{M})$ induced a higher amount of apoptosis than Sora, with $0.3 \%$ of cells in early apoptosis, $77.5 \%$ in late apoptosis and $21.6 \%$ being necrotic (Fig. 9A-d). Simultaneous combined treatment of Hep3b cells with Sora $(5 \mu \mathrm{M})$ and Cur $(200 \mu \mathrm{M})$ resulted in higher levels of apoptosis than those produced by monotreatment with either Sora or Cur $(200 \mu \mathrm{M})$, with $24.9 \%$ cells in early apoptosis, $38.5 \%$ in late apoptosis and $4.3 \%$ being necrotic (Fig. 9A-e). Simultaneous treatment with Sora $(5 \mu \mathrm{M})$ and Cur $(400 \mu \mathrm{M})$ also produced a higher level of apoptosis than treatment with Sora or Cur $(400 \mu \mathrm{M})$ alone, with $0.0 \%$ cells in early apoptosis, $90.4 \%$ in late apoptosis and 9.4\% being necrotic (Fig. 9A-f).

UT HepG2 cells exhibited only low levels of apoptosis with $0.1 \%$ cells in early apoptosis, $1.9 \%$ in late apoptosis and $7.2 \%$ being necrotic (Fig. 9B-a). Sora $(5 \mu \mathrm{M})$ induced a high level of apoptosis with $3.7 \%$ of cells in early apoptosis, $81.5 \%$ in late apoptosis and $9.8 \%$ being necrotic (Fig. 9B-b). By contrast, Cur $(200 \mu \mathrm{M})$ induced a lower amount of apoptosis than Sora, with $0.1 \%$ cells in early apoptosis, $7.7 \%$ in late apoptosis and $30.1 \%$ being necrotic (Fig. 9B-c). However, Cur $(400 \mu \mathrm{M})$ markedly induced apoptosis, with $0.0 \%$ cells in early apoptosis, $77.3 \%$ in late apoptosis and $22.9 \%$ being necrotic (Fig. 9B-d). In addition, compared with monotreatment with Sora or Cur $(200 \mu \mathrm{M})$, simultaneous combined treatment of HepG2 cells with Sora $(5 \mu \mathrm{M})$ and Cur $(200 \mu \mathrm{M})$ triggered massive apoptosis, with $0.0 \%$ cells in early apoptosis, $95.5 \%$ in late apoptosis and $4.3 \%$ being necrotic (Fig. 9B-e). Similarly, simultaneous combined treatment with Sora $(5 \mu \mathrm{M})$ and Cur (400 $\mu \mathrm{M})$ produced markedly elevated levels of apoptosis, with $0.0 \%$ of cells in early apoptosis, $93.9 \%$ in late apoptosis and $6.2 \%$ being necrotic (Fig. 9B-f).

Treatment of Hep3b cells with $\mathrm{Kmf}(200 \mu \mathrm{M})$ resulted in high levels of apoptosis with $23.5 \%$ of cells in early apoptosis, $12.8 \%$ in late apoptosis and $7.7 \%$ being necrotic (Fig. 10A-c). In addition, $\mathrm{Kmf}$ at $400 \mu \mathrm{M}$ produced higher levels of apoptosis than $\mathrm{Kmf}$ at $200 \mu \mathrm{M}$, with $49.5 \%$ of cells in early apoptosis, $23.7 \%$ in late apoptosis and $3.0 \%$ being necrotic (Fig. 10A-d). Compared with monotreatment with Sora $(5 \mu \mathrm{M})$ or $\mathrm{Kmf}(200 \mu \mathrm{M})$, their simultaneous combined treatment induced larger amounts of apoptosis with $50.9 \%$ cells in early apoptosis, $18.1 \%$ in late apoptosis and $5.4 \%$ being necrotic (Fig. 10A-e). Simultaneous combined treatment with Sora $(5 \mu \mathrm{M})$ and $\mathrm{Kmf}(400 \mu \mathrm{M})$ induced a higher level of apoptosis compared with the respective monotreatments, with $63.6 \%$ of cells in early apoptosis, $16.0 \%$ in late apoptosis, and $3.5 \%$ exhibiting necrosis (Fig. 10A-f).

Treatment of HepG2 cells with $\mathrm{Kmf}(200 \mu \mathrm{M})$ induced lower levels of apoptosis compared with those produced by Sora (5 $\mu \mathrm{M}$; Fig. 10B-b), with $0.6 \%$ cells in early apoptosis, $14.6 \%$ in late apoptosis and $19.4 \%$ exhibiting necrosis (Fig. 10B-c). Kmf $(400 \mu \mathrm{M})$ induced higher levels of apoptosis than $\mathrm{Kmf}(200 \mu \mathrm{M})$ with $11.3 \%$ of cells in early apoptosis, $37.2 \%$ in late apoptosis and $8.0 \%$ exhibiting necrosis; however, the extent of apoptosis induced by
$\mathrm{Kmf}(400 \mu \mathrm{M})$ was still lower than that produced by Sora (Fig. 10B-d). Furthermore, simultaneous combined treatment with Sora $(5 \mu \mathrm{M})$ and $\mathrm{Kmf}(200 \mu \mathrm{M})$ triggered a higher amount of apoptosis compared with monotreatment with $\mathrm{Kmf}(200 \mu \mathrm{M})$, with $8.3 \%$ of cells in early apoptosis, $77.0 \%$ in late apoptosis and $8.9 \%$ exhibiting necrosis (Fig. 10B-e). Simultaneous combined treatment with Sora $(5 \mu \mathrm{M})$ and $\mathrm{Kmf}(400 \mu \mathrm{M})$ also induced a higher level of apoptosis compared with monotreatment with $\mathrm{Kmf}(400 \mu \mathrm{M})$ and Sora, with $4.7 \%$ in early apoptosis, $80.2 \%$ in late apoptosis and $11.4 \%$ exhibiting necrosis (Fig. 10B-f).

MMP. Alterations in the MMP of the cancer cell lines were measured following mono- and combined treatments with Sora and Cur or Kmf. UT cells accumulated the MitoNIR dye in the mitochondria, resulting in increased red fluorescence intensity; however, in apoptotic cells, the NIR staining intensity decreased due to the decline in MMP. The MMP was monitored in Hep3b and HepG2 cells following monotreatment with Sora, Cur and Kmf as well as simultaneous combined treatment with Sora/Cur and Sora/Kmf. The obtained results (Figs. 11A, B and 12A, B) demonstrated that the red fluorescence of the MitoNIR dye shifted more to the left with combined treatments compared to that observed with monotreatment with Sora, Cur or Kmf. This suggests a decrease in fluorescence intensity of the MitoNIR dye and thus more extensive mitochondrial membrane damage due to the larger amount of apoptosis following combined treatment. One exception was Cur $(400 \mu \mathrm{M})$, which caused a right shift of the red fluorescence of the MitoNIR dye with HepG2, indicating no change in MMP (Fig. 11B-f). A previous study has reported that Cur inhibited UV irradiation-induced loss of MMP and cytochrome $\mathrm{C}$ release in human epidermoid carcinoma A431 cells (17). Additionally, in a recent study, pretreatment of HeLa cervical cancer cells with Cur reduced vinblastine-induced ROS production, microtubule depolymerization and the collapse of MMP (18). The inhibitory effect of Cur on apoptotic biochemical alterations triggered by several stimuli has been attributed to its anti-oxidant properties (19). Perturbation of the MMP in the HCC cells was dependent on the type of hepatic cancer cell line, the tested NPC and the combined treatment (Figs. 11A, B and 12A, B).

Effect of Sora, Cur and their simultaneous combined treatment on the expression of cell cycle-and apoptosis-associated proteins in Hep3b cells. To explore the mechanisms underlying the anticancer effects of Sora, Cur and their combination in HCC cells, the expression of cell cycle- and apoptosis-associated proteins was investigated by western blot analysis. The focus was on studying the effects of Sora, Cur and their simultaneous combinations, while the combinations of Sora and other NPCs are currently under investigation and will be reported in a separate publication. The expression levels of p27 decreased in Hep3b cells after monotreatment with Cur $(400 \mu \mathrm{M})$ and simultaneous combined treatment with Sora $(5 \mu \mathrm{M})$ and Cur $(400 \mu \mathrm{M})$ compared with those in vehicle-treated controls (Fig. 13A-a). On the other hand, a slight increase in the level of p27 was identified with a single treatment with Cur $(200 \mu \mathrm{M})$ compared with the vehicle-treated control. 
A Hep3b

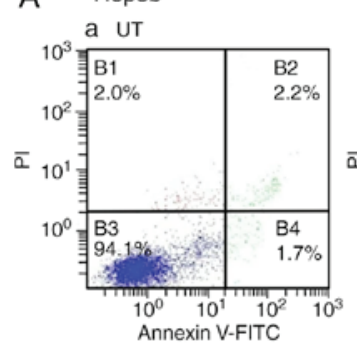

b $5 \mu \mathrm{M}$ Sora

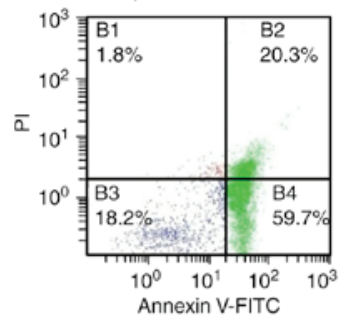

C $200 \mu \mathrm{M} \mathrm{Kmt}$

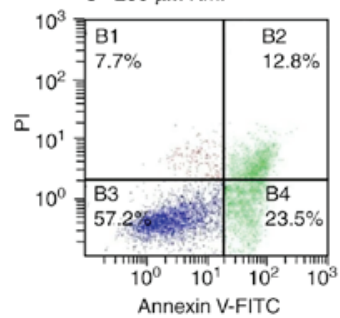

d $400 \mu \mathrm{M} \mathrm{Kmt}$

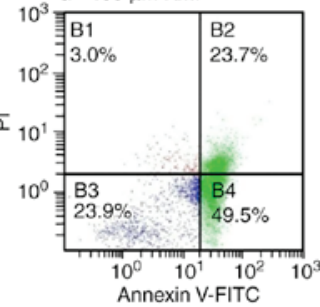

e $200 \mu \mathrm{M} \mathrm{Kmf+5 \mu M} \mathrm{Sora}$

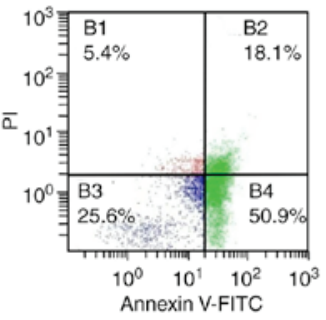

f $400 \mu \mathrm{M} \mathrm{Kmf}+5 \mu \mathrm{M}$ Sora

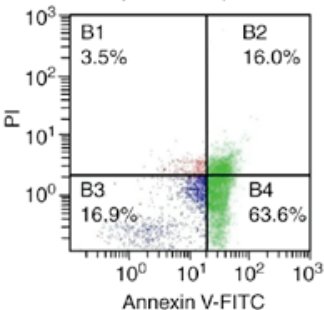

B HepG2

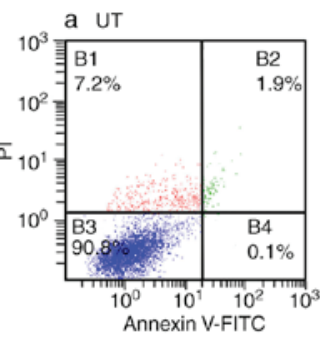

b $5 \mu \mathrm{M}$ Sora

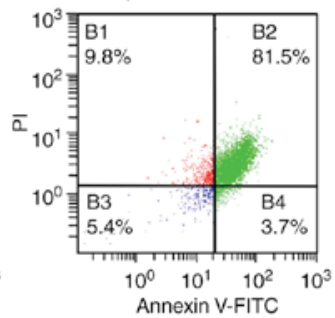

C $200 \mu \mathrm{M} \mathrm{Kmf}$

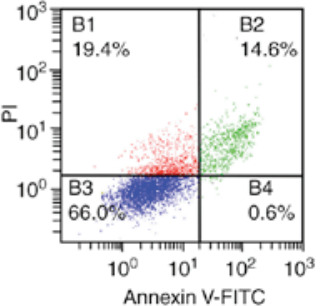

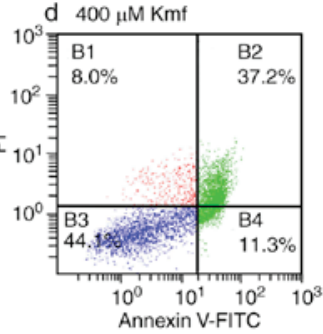

e $200 \mu \mathrm{M} \mathrm{Kmf}+5 \mu \mathrm{M}$ Sora

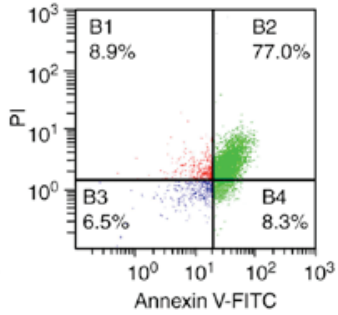

f $400 \mu \mathrm{M} \mathrm{Kmf}+5 \mu \mathrm{M}$ Sora

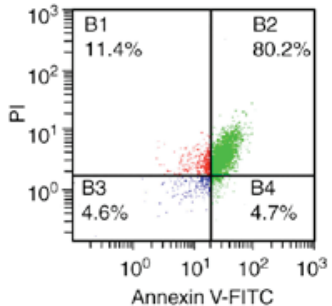

Figure 10. Flow cytometric analysis of apoptosis in human hepatic cancer cell lines treated with Sora, Kmf and their simultaneous combinations. (A) Hep3b and (B) HepG2 hepatic cancer cell lines were (a) left untreated or treated with (b) Sora $(5 \mu \mathrm{M})$, (c) Kmf $(200 \mu \mathrm{M})$, (d) Kmf (400 $\mu \mathrm{M})$, or (e and f) simultaneous combinations of Sora and $\mathrm{Kmf}(5 \mu \mathrm{M}+200 \mu \mathrm{M}$, respectively) or $(5 \mu \mathrm{M}+400 \mu \mathrm{M}$, respectively) for $48 \mathrm{~h}$. The cells were analyzed by flow cytometry after processing and staining with Annexin V-FITC/PI. B1, percentage of necrotic cells; B2, percentage of late apoptotic cells; B3, percentage of viable cells; and B4, percentage of early apoptotic cells. Sora, sorafenib; Kmf, kaempferol; UT, untreated; PI, propidium iodide; FITC, fluorescein isothiocyanate.
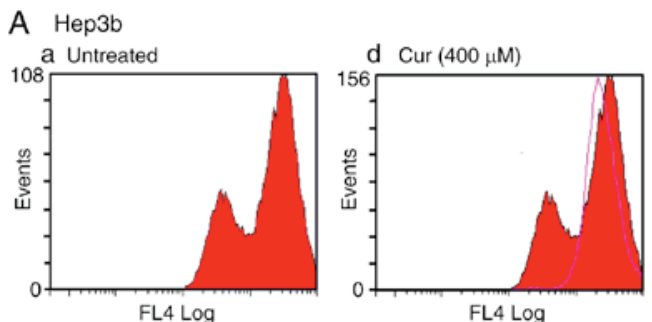

B HepG2

a Untreated

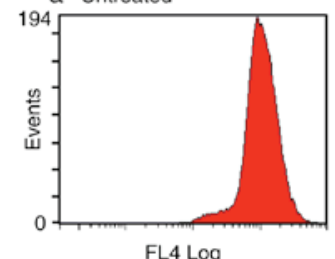

FL4 Log
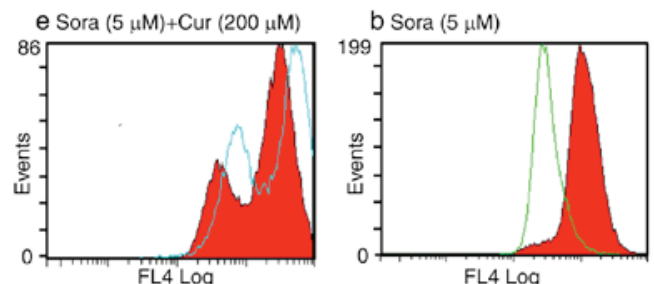

f Sora $(5 \mu \mathrm{M})+\mathrm{Cur}(400 \mu \mathrm{M})$
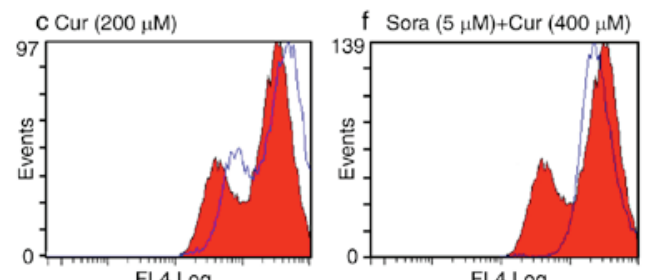

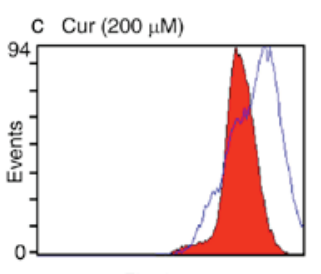

FL4 Log d Cur $(400 \mu \mathrm{M})$

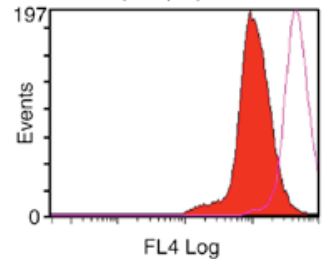

e Sora $(5 \mu \mathrm{M})+\operatorname{Cur}(200 \mu \mathrm{M})$
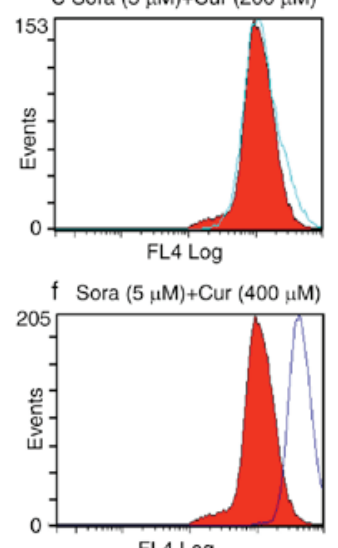

Figure 11. Flow cytometric analysis of MMP in human hepatic cancer cell lines treated with Sora, Cur and their simultaneous combinations. (A) Hep3b and (B) HepG2 hepatic cancer cell lines were (a) left untreated or treated with (b) Sora (5 $\mu \mathrm{M})$, (c) Cur (200 $\mu \mathrm{M})$, (d) Cur ( $400 \mu \mathrm{M})$, or (e and f) simultaneous combinations of Sora and Cur $(5 \mu \mathrm{M}+200 \mu \mathrm{M}$, respectively) or $(5 \mu \mathrm{M}+400 \mu \mathrm{M}$, respectively) for $48 \mathrm{~h}$. Alterations in MMP were monitored by staining with the MitoNIR dye and flow cytometric analysis with excitation/emission wavelengths of 635 and $660 \mathrm{~nm}$, respectively. The red and white curves are the control and experimental groups, respectively. MMP, mitochondrial membrane potential; Sora, sorafenib; Cur, curcumin. 
A Hep3b
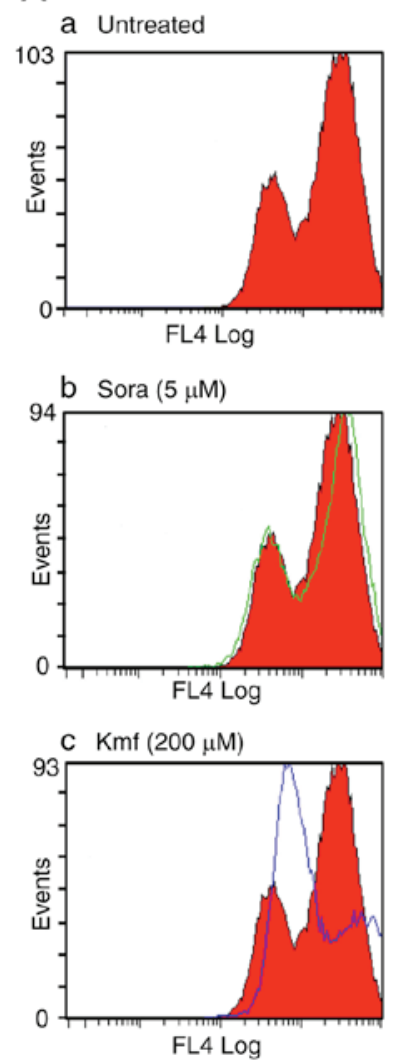

d $\mathrm{Kmf}(400 \mu \mathrm{M})$

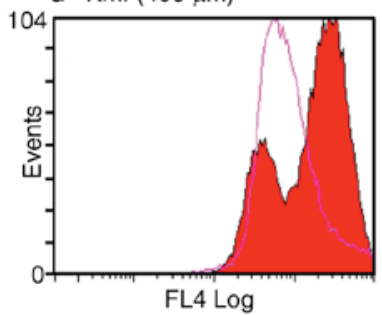

e Sora $(5 \mu \mathrm{M})+\mathrm{Kmf}(200 \mu \mathrm{M})$

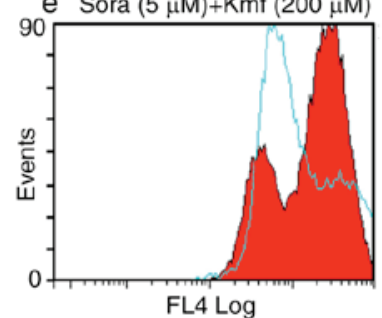

FL4 Log

f Sora $(5 \mu \mathrm{M})+\mathrm{Kmf}(400 \mu \mathrm{M})$

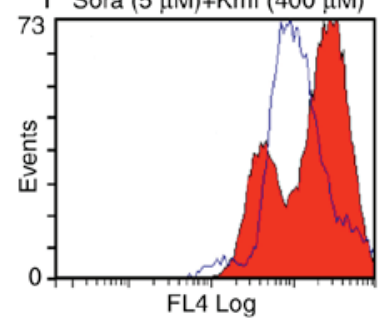

B HepG2

a Untreated

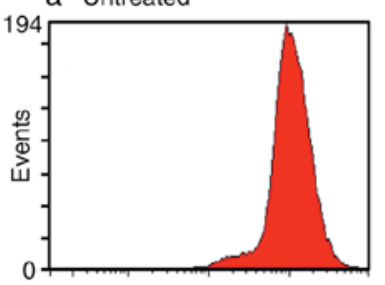

FL4 Log

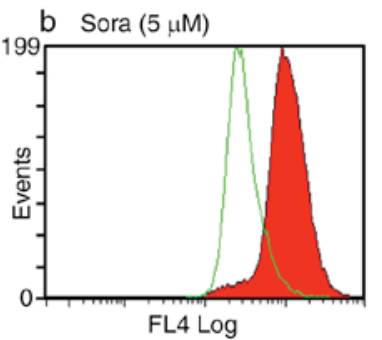

C $\mathrm{Kmf}(200 \mu \mathrm{M})$

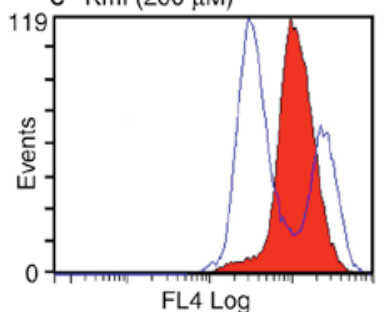

d $\mathrm{Kmf}(400 \mu \mathrm{M})$

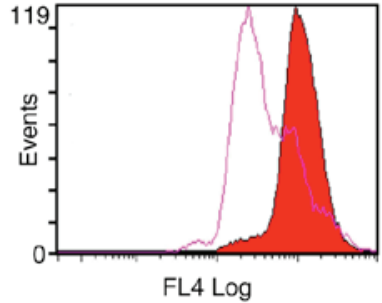

e Sora $(5 \mu M)+K m f(200 \mu M)$

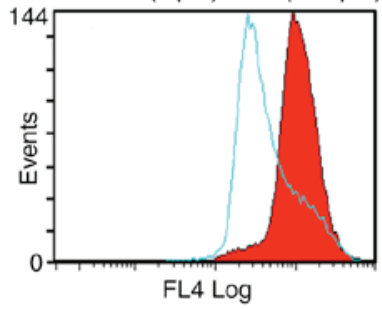

f Sora $(5 \mu \mathrm{M})+\mathrm{Kmf}(400 \mu \mathrm{M})$

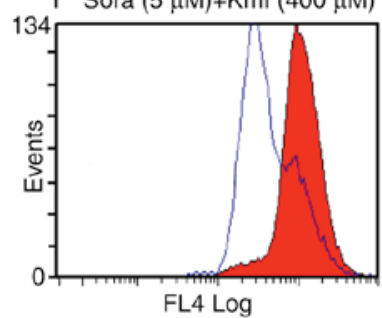

Figure 12. Flow cytometric analysis of MMP in human hepatic cancer cell lines treated with Sora, Kmf and their simultaneous combinations. (A) Hep3b and (B) HepG2 hepatic cancer cell lines were (a) left untreated or treated with (b) Sora $(5 \mu \mathrm{M})$, (c) Kmf $(200 \mu \mathrm{M})$, (d) Kmf $(400 \mu \mathrm{M})$, or (e and f) simultaneous combinations of Sora and $\mathrm{Kmf}(5 \mu \mathrm{M}+200 \mu \mathrm{M}$, respectively) or $(5 \mu \mathrm{M}+400 \mu \mathrm{M}$, respectively) for $48 \mathrm{~h}$. Alterations in MMP were monitored by staining with the MitoNIR dye and flow cytometric analysis with excitation/emission wavelengths of 635 and $660 \mathrm{~nm}$, respectively. Alterations in MMP were monitored by staining with the MitoNIR dye and flow cytometric analysis with excitation/emission wavelengths of $635 \mathrm{and} 660 \mathrm{~nm}$, respectively. The red and white curves are the control and experimental groups, respectively. MMP, mitochondrial membrane potential; Sora, sorafenib; Kmf, kaempferol.

A

Cell cycle - related proteins

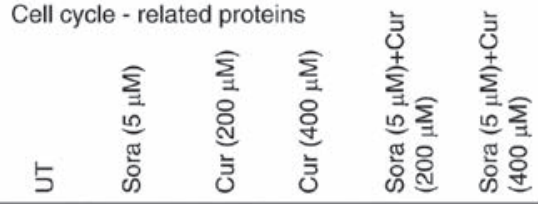

a p27

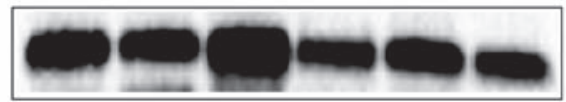

b Cyclin A2

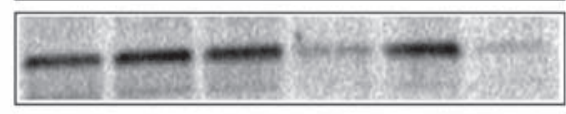

a $B a x$

B Apoptosis - related proteins

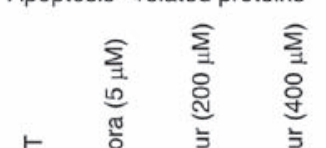

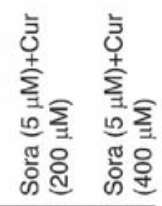

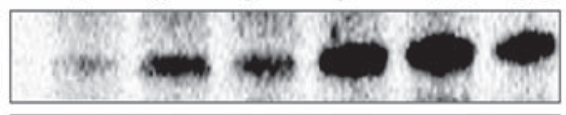

C Cyclin B

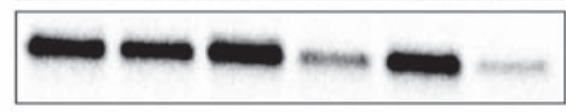

d Cyclin D1

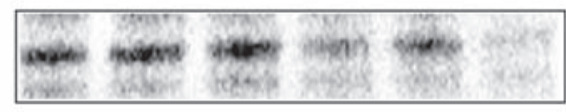

e pRB

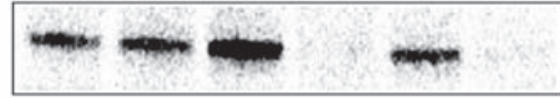

f $\beta$-actin
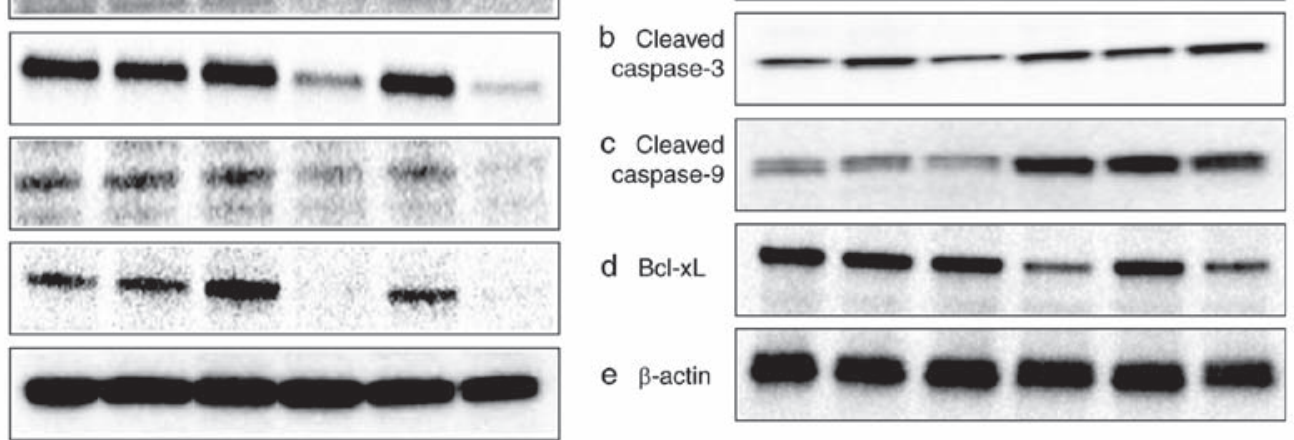

Figure 13. Western blot analysis of the levels of cell cycle and apoptosis-associated proteins in the extract of human hepatic cancer cell lines Hep3b and HepG2 treated with Sora, Cur, and their combinations. The cells were treated with Sora $(5 \mu \mathrm{M})$, Cur $(200 \mu \mathrm{M})$, Cur $(400 \mu \mathrm{M})$ or a simultaneous combination of Sora and Cur $(5 \mu \mathrm{M}+200$ or $400 \mu \mathrm{M})$ for $48 \mathrm{~h}$. The levels of proteins associated with the control of cell cycle and apoptosis were analyzed by western blot analysis. Signal intensities of the respective bands were densitometrically quantified. (A) Cell cycle-associated proteins and (B) apoptosis-associated proteins. Sora, sorafenib; Cur, curcumin; UT, untreated; pRb, retinoblastoma protein; Bcl-xL, B-cell lymphoma extra-large protein; Bax, B-cell lymphoma 2-associated $\mathrm{X}$ protein. 
Furthermore, the levels of cyclin A2, cyclin B, cyclin D1 and $\mathrm{pRb}$ proteins were markedly decreased in Hep3b cells following simultaneous treatment with Sora/Cur $(400 \mu \mathrm{M})$ and monotreatment with Cur $(400 \mu \mathrm{M})$. On the other hand, $\mathrm{pRb}$ and cyclin B levels slightly increased following treatment with Cur $(200 \mu \mathrm{M})$ compared with the UT group. (Fig. 13A-b-e). The levels of the pro-apoptotic proteins Bax (Fig. 13B-a), cleaved-caspase-3 (Fig. 13B-b) and cleaved-caspase-9 (Fig. 13B-c) were markedly increased. On the other hand, the expression of the anti-apoptotic protein $\mathrm{Bcl}-\mathrm{xL}$ was decreased following mono- and simultaneous combined treatment with Sora $(5 \mu \mathrm{M})$ and $\operatorname{Cur}(400 \mu \mathrm{M})$ and slightly decreased following single treatment with Cur $(200 \mu \mathrm{M})$ and simultaneous combined treatment with Sora $(5 \mu \mathrm{M})$ and Cur $(200 \mu \mathrm{M}$; Fig. 13B-d). $\beta$-actin expression was used as an internal control to monitor the protein loaded onto the gel (Fig. 13A-f and B-e).

\section{Discussion}

Sora has been approved by the FDA for the clinical treatment of HCC and renal cell carcinomas (20). However, up to $80 \%$ of Sora-treated patients experience toxic side effects, including hand-foot syndrome, diarrhea, fatigue, rash and weight loss (21). Due to these adverse side effects, a dose reduction was necessary in $>60 \%$ of the patients and in $6-25 \%$ of patients, treatment was discontinued according to a previous study (21).

Sora has several properties that suggest it may be useful as part of a combination treatment for patients with advanced cancer. Sora's multiple targets include Raf-1 (22), wild-type B-Raf, oncogenic b-raf V600E and pro-angiogenic receptor tyrosine kinases (23), enabling it to act on the tumor and tumor vasculature to induce apoptosis, inhibit proliferation and angiogenesis, and providing Sora with the potential for activity against a wide variety of tumor types (24).

Considerable efforts have been made to improve the therapeutic efficacy and reduce the side effects of Sora, as well as to overcome resistance against it. Combination therapy that allows for a dose reduction of Sora without decreasing its efficacy may be an option to minimize its adverse effects and overcome drug resistance (25).

Investigation of the efficacy of plant-derived drugs has received increasing attention owing to their excellent chemotherapeutic and chemopreventive activities, besides the fact that they are thought to be well-tolerated, non-toxic, easily available and inexpensive (11); furthermore, bioactive natural products may act in synergy with drugs used in cancer therapy $(26,27)$.

Combination therapy of Sora with another chemotherapeutic agent is currently not utilized in clinical practice. However, combining drugs with different mechanisms of action is theoretically a rational approach in the treatment of hepatocellular carcinoma $(3,28)$. Therefore, the development of an effective cancer chemotherapeutic approach and/or combination with an agent with fewer side effects is urgently required for improving the management of cancer patients treated with Sora.

The goal of the present study was to investigate the ability of a panel of NPCs to potentiate the anticancer effects of
Sora in hepatic cancer cells, i.e. whether combined therapy with NPCs allows for a dose reduction of Sora without the concomitant loss of effectiveness. The present study aimed to identify the best drug combinations and the best combined administration strategies as well as the potential underlying molecular mechanisms of action.

The cytotoxic effect of Sora and the panel of 14 NPCs, including Kmf, Que, Rsv, Cur, Irt, Snn, Sil, Sul, Lyp, Hsp, BetA, Cmr, I3C and HHG, was initially examined in the CRL1554 normal human fibroblast cell line. Sora exhibited a marked growth inhibitory effect (\% cytotoxicity=4.76-100). However, the tested NPCs demonstrated variable cytotoxic effects ranging from 0 to $100 \%$; only those with little $(<20 \%$, Que) or no cytotoxic effects (Cur, Rsv, and Kmf) on the normal fibroblast cell line were selected for further testing in combination studies. Based on the dose-dependent anticancer activity on hepatic cancer cell lines, the concentrations of 60 or $120 \mu \mathrm{M}$ for Cur, Que and $\mathrm{Kmf}$, as well as 40 or $80 \mu \mathrm{M}$ for Rsv were selected for testing the various combination approaches. Sora was used at a concentration range of $2.5-10 \mu \mathrm{M}$, as this falls within the clinically relevant range achievable in plasma (5-15 $\mu \mathrm{M})(29)$.

In the present study, various schedules of administration of Sora and NPCs (Cur, Kmf, Que and Rsv) were tested in the human hepatic cancer cell lines Hep3b and HepG2. NPCs potentiate the lethality of Sora in the following order: Cur $>\mathrm{Kmf}>\mathrm{Rsv}>$ Que, in a dose-, hepatic cancer cell type-, NPC type- and administration schedule-dependent manner. The present results are in agreement with the results reported in a series of combination studies with Sora and different anticancer agents used in the treatment of various solid tumor types. For instance, combination treatment with fisetin and Sora reduced the growth of human melanoma cells harboring b-Raf mutation more effectively and at lower doses compared with treatment with individual agents (30). Fisetin also potentiated the Sora-mediated reduction of colony formation by melanoma cells harboring a b-Raf mutation and enhanced apoptosis. In athymic nude mice subcutaneously implanted with melanoma cells (A375 and SK-MEL-28), combined treatment with fisetin and Sora resulted in a greater reduction of tumor growth when compared to the individual agents (30).

Recently, sulforaphane (SF), a naturally occurring isothiocyanate that is highly concentrated in broccoli sprouts, was reported to eliminate pancreatic cancer stem cells via downregulation of nuclear factor- $\kappa \mathrm{B}$ activity, without inducing toxic side effects (31). Sora and SF synergistically inhibited pancreatic cancer stem cells in vitro. This combination therapy resulted in a more pronounced induction of cell death than monotreatment with either substance alone, as indicated by analysis of cell morphology, as well as colony and spheroid formation (31). In vivo, monotreatment with Sora or SF alone retarded tumor growth; however, combined treatment with SF and Sora was more potent and significantly reduced tumor growth (31).

In addition, combined treatment with Que and Sora produced a synergistic anti-proliferative effect on the human hepatic cancer cell lines HepG2, HuH7 and Hep4B2.1 (31). Combination of Sora with Que also resulted in an effective cell type-specific apoptosis in anaplastic astrocytoma cells; the percentage of dead cells was higher than that observed 
after monotreatment with Sora (32). Furthermore, the combination of nanocurcumin and Sora produced stronger antitumor effects in HCC cells than either nanocurcumin or Sora alone; it also inhibited HCC cell migration and invasion. The combination of nanocurcumin and Sora also increased the apoptosis of HCC cells in vitro and in vivo (33).

Furthermore, Sora curcumin nanoparticles (SCN) exerted superior in vitro cytotoxic effects over those of Sora, Cur and their physical mixture (Sora + Cur) on the hepatic cancer cell lines BEL-7402 and HepG2 (34). In xenografts derived from BEL7402 cells, SCN treatment exhibited an obviously enhanced inhibitory effect on tumor progression compared with monotherapy or the physical mixture of Sora and Cur, with significantly increased anti-proliferative and anti-angiogenic capabilities (34).

In vitro, the combination of Sora and YC-1, a soluble guanylyl cyclase activator, synergistically inhibited the proliferation and colony formation of the hepatic cancer cell lines HepG2, BEL-7402 and HCCLM3 (35). In vivo, combined treatment with Sora and YC-1 significantly suppressed the growth of HepG2 cell-derived xenograft tumors with decreased cell proliferation and increased apoptosis (35).

In vitro, sequential radiation treatment (RT) followed by Sora treatment of the hepatic cancer cell lines $\mathrm{HuH7}$, Hep3b, HCC-4-4 and HepG2 increased apoptosis compared with RT alone, while concurrent treatment produced apoptotic rates similar to those obtained with RT alone and led to decreased colony formation in all of the 4 cell lines (36). In vivo, sequential RT/Sora treatment produced the greatest tumor growth delay, while the effect of simultaneous RT/Sora treatment was identical to that of RT alone (36). Sequential RT/Sora treatment also produced a greater reduction in xenograft tumor vascularity and mitotic index than either simultaneous RT/Sora or RT alone. Thus, sequential $\mathrm{RT} /$ Sora demonstrated greater efficacy against hepatic cancer than simultaneous RT/Sora treatment in vitro and in vivo.

Finally, Sora and metformin synergistically inhibited the growth of the anaplastic thyroid carcinoma cell line HTh-74 and its derivative, the doxorubicin-resistant HTh74Rdox cell line, with a more pronounced effect on HTh74Rdox cells. The two drugs also synergistically decreased sphere formation, which suggested a specific effect on thyroid cancer stem cells. The addition of metformin allowed for a $25 \%$ dose reduction of Sora without the loss of its growth-inhibitory efficacy (37). A potentiating effect of metformin as chemosensitizer to Sora has recently been reported in cholangiocarcinoma cells (38). In the present study, the growth inhibition assay indicated that simultaneous combined treatment with Sora/Cur and Sora/Kmf was effective against Hep3b and HepG2 cells, with HepG2 being more sensitive than Hep3b cells. Thus, it may be concluded that the effectiveness of combined treatment of cancer cells with Sora and NPCs depends on the type of cancer cell, the type and dose of the NPCs, and the mode of administration. Exploration of the potential mechanism of the combined treatment with Sora and NPCs was focused on the most effective schedule of administration, namely the simultaneous treatment with Sora and Cur or Kmf.

Cell growth and proliferation are controlled by the cell cycle, and its disruption causes an imbalance between proliferation and cell death, leading to cancer growth. Thus, anticancer agents targeting the cell cycle may halt the uncontrolled proliferation of cancer cells and initiate apoptosis (39). Cell growth is normally controlled by several genetically defined checkpoints that ensure its coordinated progression through the different stages of the cell cycle and monitor DNA integrity (40). In the present study, analysis of the cell cycle and apoptosis was used to elucidate the mechanisms involved in the synergistic effects of Cur or Kmf with Sora in the treatment of Hep3b and HepG2 cells. The results indicated that combined treatment of the hepatic cancer cell lines with Sora/Cur and Sora/Kmf resulted in cell growth inhibition in the S-phase and/or $\mathrm{G}_{2} / \mathrm{M}$-phase, depending on the type of cancer cell and schedule of treatment. The subG1 phase, which is comprised of apoptotic cell bodies, is increased due to induction of apoptosis by these combined treatments (41) and also by the majority of cancer drugs (42).

Disruption of the cell cycle progression at the S-phase implies that the tested combinations interfere with DNA synthesis and disrupt the progression of the cell cycle past the S-phase, leading to apoptosis; furthermore, blocking damaged cells in the $\mathrm{G}_{2} / \mathrm{M}$-phase allows ample time for DNA damage repair or permanent obstruction of the damaged cells (43). Numerous anticancer agents have been reported to induce apoptotic cell death by arresting the cell cycle at the $\mathrm{G}_{2} / \mathrm{M}$-phase (44). Cell cycle arrest in $\mathrm{G}_{2} / \mathrm{M}$-phase involves disruption of the tubulin-microtubule equilibrium (45), suggesting that $\mathrm{G}_{2} / \mathrm{M}$ arrest may have a role in the inhibition of microtubule dynamics.

Induction of apoptosis of tumor cells is considered expedient in the treatment of cancer (46). However, one of the challenges in cancer treatment is the ability of cancer cells to evade apoptosis. As a safeguard mechanism against tumorigenesis and due to genetic and epigenetic alterations (47), neoplastic cells become resistant to apoptosis, rendering cytotoxic drugs ineffective.

In the present study, induction of apoptosis by Sora, NPCs (Cur and Kmf) and their combinations was monitored in hepatic cancer cell lines by assaying DNA fragmentation, Annexin-V/PI double staining and MMP. The results clearly indicate that the apoptotic effect of mono- and combined treatments was dependent on the type of NPC, type of Sora/NPC combination and schedule of treatment. These results are consistent with those reported for various combinations of Sora in different types of tumor $(30,33,34,37)$. Combined treatment of Hodgkin lymphoma cell lines with perifosine/Sora significantly induced severe mitochondrial dysfunction and necrotic cell death in a synergistic manner compared with treatment with single agents (48). In vivo xenograft studies demonstrated a significant induction of apoptosis and necrosis in perifosine/Sora-treated mice compared with that in mice receiving single agents (48). Furthermore, combination treatment with Rsv and Sora promoted apoptosis in HCC-bearing mice (49).

The expression of genes associated with cell cycle and apoptosis after treatment with Sora, Cur and their simultaneous combined treatments, the most effective regimen among the tested combinations and administration schedules, was monitored at the translation level using western blot analysis. The results indicated that the expression levels of 
the Cdk inhibitor $\mathrm{p} 27^{\mathrm{KIP} 1}$ decreased in Hep3b cells following monotreatment with Cur $(400 \mu \mathrm{M})$ and simultaneous treatment with Sora $(5 \mu \mathrm{M}) / \mathrm{Cur}(200$ or $400 \mu \mathrm{M})$ compared with those in vehicle-treated controls. The expression levels of cyclin A2, cyclin B, cyclin D1 and p-pRb were decreased in Hep3b cells following simultaneous treatment with Sora/Cur $(400 \mu \mathrm{M})$ and monotreatment with Cur $(400 \mu \mathrm{M})$. However, the levels of these proteins were slightly decreased following simultaneous combined treatment with Sora and Cur $(200 \mu \mathrm{M})$. Cyclin D1 is required for cell cycle progression in G1 phase and inhibition of its expression causes a block of the $\mathrm{G}_{1} / \mathrm{S}$ checkpoint (50).

Sora has been reported to induce growth suppression in a renal cell carcinoma (RCC) cell line and RCC-induced xenografts and inhibit the expression of cyclin D1 and cyclin B1 (50). A study on the HCC cell lines HLE, HLF, PLC/PRF/5, Huh-7 and Hep3b and the hepatoblastoma cell line Huh6 treated with Sora demonstrated a decrease in the expression levels of cyclin D1 and an increase in the levels of cleaved caspase-3. It also inhibited cell cycle progression and induced apoptosis (51). Combined treatment of the colorectal cancer cell line HT-29 with Sora and RT was reported to enhance the cytotoxicity of Sora; however, Sora alone induced the accumulation of tumor cells in the $\mathrm{G}_{2} / \mathrm{M}$ phase and decreased the expression of cyclin B1 (52).

In the present study, the expression of the pro-apoptotic proteins Bax, cleaved-caspase- 3 and cleaved-caspase- 9 was markedly increased, while the expression of the anti-apoptotic protein Bcl-xL was suppressed by simultaneous combined treatment of Hep3b cells with Sora/Cur. An increased $\mathrm{Bax} / \mathrm{Bcl}-\mathrm{xL}$ ratio leads to apoptosis via a collapse of the MMP, cytochrome $c$ release and caspase-3 activation (53). In addition, the pro-apoptotic protein Bax is closely associated with the control of mitochondrial membrane permeability and release of cytochrome $c$ (54). A study on HCC cell lines and xenografts treated with Sora revealed proteolytic activation of caspase- 3 and -9 , indicating that Sora may trigger mitochondrial-mediated apoptosis (55). A recent study indicated that Sora triggered caspase-dependent Bcl-xL protein degradation, destabilized the mitochondria and induced rapid apoptosis in myeloma cells (56). The results of the present study demonstrated that simultaneous combined treatment of hepatic cancer cells with Sora and Cur caused $\mathrm{G}_{2} / \mathrm{M}$ - and S-phase arrest and markedly induced their apoptosis. Cur induced apoptosis through activation of multiple signaling pathways. Cur induced the expression of pro-apoptotic proteins (Bax, cleaved caspase-3 and cleaved caspase-9) and inhibited the expression of the anti-apoptotic protein Bcl-xL. Based on these observations, treatment with Cur is likely to result in translocation of Bax to the mitochondria, production of reactive oxygen species, a drop in MMP, release of mitochondrial proteins and induction of apoptosis.

A growing body of evidence has demonstrated that Sora reduced the expression of the oncoprotein $\beta$-catenin, particularly in HepG2 cells. In addition, exposure of HepG2 cells to Sora activated c-Jun N-terminal kinase (JNK) and p38 MAPK stress-associated pathways, with the two signaling pathways having opposite roles in Sora-induced cell growth inhibition, from cytoprotective in the case of $\mathrm{JNK} / \mathrm{c}$-Jun activation to cytotoxic in the case of $\mathrm{p} 38$ MAPK activation (57). In addition, a number of genes involved in DNA repair and recombination, as well as cell cycle regulation, were previously reported to be downregulated by Sora (57).

When Cur was combined with Sora, Cur augmented the apoptosis-inducing potential of Sora. The synergistic inhibition of cancer cell growth observed in the present study may be explained by considering the target pathways of Sora and the various NPCs. It appears that the MAPK pathway is a common target for Sora and certain NPCs. In addition, Sora and certain NPCs inhibit other growth-regulatory signaling pathways and exert anti-mitogenic effects on hepatic cancer cell lines. The synergistic effects of certain NPCs suggest that these agents may be utilized as chemosensitizers to Sora treatment, and may reduce the dose-dependent side effects of Sora by allowing for its dose reduction. However, additional, detailed in vivo studies are necessary to evaluate whether the combination of Sora with bioactive natural products is effective in the treatment of hepatic cancer and possibly other types of human cancer. Future issues, including the optimal combinations, treatment schedules and dosages of Sora combinations for a variety of tumor types should be investigated to determine whether combinations of Sora with certain NPCs offer survival benefits in patients with advanced cancer.

\section{Acknowledgements}

The authors would like to thank the Biotechnology Center (BTC) at Kuwait University for their technical support.

\section{Funding}

This study was supported by Kuwait University (research grant no. YS01/15).

\section{Availability of data and materials}

All data generated or analyzed during this study are included in this published article.

\section{Authors' contributions}

$\mathrm{AAB}$ and MSIA equally contributed to the design of the current study and writing the manuscript. AAB, MSIA, SIK and RJA equally contributed in executing the analysis of the cell cycle, MMP and apoptosis. AAB, MSIA and SIK equally contributed in executing all the other experiments.

\section{Ethics approval and consent to participate}

Not applicable.

\section{Patient consent for publication}

Not applicable.

\section{Competing interests}

The authors declare they have no competing interests. 


\section{References}

1. Yu MC and Yuan JM: Environmental factors and risk for hepatocellular carcinoma. Gastroenterology 127: S72-S78, 2004.

2. Bosch FX, Ribes J, Diaz M and Cléries R: Primary liver cancer: Worldwide incidence and trends. Gastroenterology 127: S5-S16, 2004

3. LIovet JM and Bruix J: Molecular targeted therapies in hepatocellular carcinoma. Hepatology 48: 1312-1327, 2008.

4. LIovet JM, Ricci S, Mazzaferro V, Hilgard P, Gane E, Blanc JF, de Oliveira AC, Santoro A, Raoul JL, Forner A, et al: Sorafenib in advanced hepatocellular carcinoma. N Engl J Med 359: 378-390, 2008

5. Wilhelim SM, Adnane L, Newell P, Villanueva A, LIovet JM and Lynch M: Preclinical overview of sorafenib, a multikinase inhibitor that targets both Raf and VEGF and PDGF receptor tyrosine kinase signaling. Mol Cancer Ther 7: 3129-3140, 2008.

6. Furuse J: Sorafenib for the treatment of unresectable hepatocellular carcinoma. Biologics 2: 779-788, 2008.

7. Hartmann JT, Haap M, Kopp HG and Lipp HP: Tyrosine kinase inhibitors-a review on pharmacology, metabolism and side effects. Curr Drug Metab 10: 470-481, 2009.

8. Shen YC, Ou DL, Hsu C, Lin KL, Chang CY, Lin C, Liu SH and Cheng AL: Activating oxidative phosphorylation by a pyruvate dehydrogenase kinase inhibitor overcomes sorafenib resistance of hepatocellular carcinoma. Br J Cancer 108: 72-81, 2013.

9. Pezzuto JM: Plant-derived anticancer agents. Biochem Pharmacol 53: 121-133, 1997.

10. Newman DJ, Cragg GM, Holbeck S and Sausville EA: Natural products and derivatives as leads to cell cycle pathway targets in cancer chemotherapy. Curr Cancer Drug Targets 2: 279-308, 2002.

11. Sak K: Chemotherapy and dietary phytochemical agents. Chemother Res Pract 2012: 282570, 2012.

12. Granado-Serrano AB, Martín MA, Bravo L, Goya L and Ramos S: Quercetin induces apoptosis via caspase activation, regulation of Bcl-2, and inhibition of PI-3-kinase/Akt and ERK pathways in a human hepatoma cell line (HepG2). J Nutr 136: 2715-2721, 2006.

13. Qiu GH, Xie X, Xu F, Shi X, Wang Y and Deng L: Distinctive pharmacological differences between liver cancer cell lines HepG2 and Hep3B. Cytotechnology 67: 1-12, 2015.

14. López-Terrada D, Cheung SW, Finegold MJ and Knowles BB: HepG2 is a hepatoblastoma-derived cell line. Hum Pathol 40: $1512-1515,2009$.

15. Abaza MS, Al-Saffar A, Al-Sawan S and Al-Attiyah R: c-myc antisense oligonucleotides sensitize human colorectal cancer cells to chemotherapeutic drugs. Tumor Biol 29: 287-303, 2008.

16. Hassan M, Watari H, AbuAlmaaty A, Ohba Y and Sakuragi N: Apoptosis and molecular targeting therapy in cancer. Biomed Res Int 2014: 150845, 2014.

17. Chan W, Wu C and Yu J: Curcumin inhibits UV irradiation-induced oxidative stress and apoptotic biochemical changes in human epidermoid carcinoma A431 cells. J Cell Biochem 90: 327-338, 2003

18. Lee J, Park S, Kim S, Um S and Moon E: Curcumin hampers the antitumor effect of vinblastine via the inhibition of microtubule dynamics and mitochondrial membrane potential in Hela cervical cancer cells. Phytomedicine 23: 705-713, 2016.

19. Ruby AJ, Kuttan G, Babu KD, Rajasekharan KN and Kuttan R: Antitumor and antioxidant activity of natural curcuminoids. Cancer Lett 94: 79-83, 1995.

20. Strumberg D: Preclinical and clinical development of the oral multikinase inhibitor sorafenib in cancer treatment. Drugs Today (Barc) 41: 773-784, 2005.

21. Shen C, Qiu Z and Luo Q: Sorafenib in the treatment of radioiodine-refractory differentiated thyroid cancer: A meta-analysis. Endocr Relat Cancer 21: 253-261, 2014.

22. Wilhelm S and Chien DS: Bay 43-9006: Preclinical data. Curr Pharm Des 8: 2255-2257, 2002.

23. Wilhelm SM, Carter C, Tang L, Wilkie D, McNabola A, Rong H, Chen C, Zhang X, Vincent P, McHugh M, et al: Bay 43-9006 exhibits broad spectrum oral antitumor activity and targets the $\mathrm{RAF} / \mathrm{MEK} / \mathrm{ERK} /$ pathway and receptor kinases involved in tumor progression and angiogenesis. Cancer Res 64: 7099-7109, 2004.

24. Panka DJ, Wang W, Atkins MB and Mier JW: The Raf inhibitor Bay 43-9006 (Sorafenib) induces caspase-independent apoptosis in melanoma cells. Cancer Res 66: 1611-1619, 2006.
25. Wilhelm S, Carter C, Lynch M, Lowinger T, Dumas J, Smith RA, Schwartz B, Simantov R and Kelley S: Discovery and development of sorafenib: A multikinase inhibitor for treating cancer. Nat Rev Drug Discov 5: 835-844, 2006.

26. Jakubowicz-Gil J, Langner E and Rzeski W: Kinetic studies of the effects of Temodal and quercetin on astrocytoma cells. Pharmacol Rep 63: 403-416, 2011.

27. Jakubowicz-Gil J, Langner E, Bądziul D, Wertel I and Rzeski W: Apoptosis induction in human glioblastoma multiform T98G cells upon temozolomide and quercetin treatment. Tumour Biol 34: 2367-2378, 2013.

28. Wang Z, Zhou J, Fan J, Qiu SJ, Yu Y, Huang XW and Tang ZY: Effect of rapamycin alone and in combination with sorafenib in an orthotopic model of human hepatocellular carcinoma. Clin Cancer Res 14: 5124-5130, 2008

29. Clark JW, Eder JP, Ryan D, Lathia C and Lenz HJ: Safety and pharmacokinetics of the dual action Raf kinase and vascular endothelial growth factor receptor inhibitor, BAY 43-9006, in patients with advanced, refractory solid tumors. Clin Cancer Res 11: 5472-5480, 2005.

30. Pal HC, Baxter RD, Hunt KM, Agarwal J, Elmets CA, Athar M and Afaq F: Fisetin, a phytochemical, potentiates sorafenib-induced apoptosis and abrogates tumor growth in athymic nude mice implanted with BRAF-mutated melanoma cells. Oncotarget 6 : 28296-28311, 2015.

31. Rausch V, Liu L, Kallifatidis G, Baumann B, Mattern J, Gladkich J, Wirth T, Schemmer P, Büchler MW, Zöller M, et al: Synergistic activity of sorafenib and sulforaphane abolishes pancreatic cancer stem cell characteristics. Cancer Res 70: 5004-5013, 2010.

32. Jakubowicz-Gil J, Langner E, Badziul D, Wertel I and Rzeski W: Quercetin and sorafenib as a novel and effective couple in programmed cell death induction in human gliomas. Neurotox Res 26: 64-77, 2014

33. Hu B, Sun D, Sun C, Sun YF, Sun HX, Zhu QF, Yang XR, Gao YB, Tang WG, Fan J, et al: A polymeric nanoparticle formulation of curcumin in combination with sorafenib synergistically inhibits tumor growth and metastasis in an orthotopic model of human hepatocellular carcinoma. Biochem Biophys Res Commun 468: 525-532, 2015.

34. Cao H, Wang Y, He X, Zhang Z, Yin Q, Chen Y, Yu H, Huang Y, Chen L, Xu M, et al: Codelivery of sorafenib and curcumin by directed self-assembled nanoparticles enhances therapeutic effect on hepatocellular carcinoma. Mol Pharm 12: 922-931, 2015.

35. Kong J, Kong F, Gao J, Zhang Q, Dong S, Gu F, Ke S, Pan B, Shen Q, Sun H, et al: YC-1 enhances the anti-tumor activity of sorafenib through inhibition of signal transducer and activator of transcription 3 (STAT3) in hepatocellular carcinoma. Mol Cancer 13: 7-13, 2014

36. Wild AT, Gandhi N, Chettiar ST, Aziz K, Gajula RP, Williams RD, Kumar R, Taparra K, Zeng J, Cades JA, et al: Concurrent versus sequential sorafenib therapy in combination with radiation for hepatocellular carcinoma. PLoS One 8: e65726, 2013.

37. Chen G, Nicula D, Renko K and Derwahl M: Synergistic anti-proliferative effect of metformin and sorafenib on growth of anaplastic thyroid cancer cells and their stem cells. Oncol Rep 33: 1994-2000, 2015.

38. Ling S, Feng T, Ke Q, Fan N, Li L, Li Z, Dong C, Wang C, Xu F, $\mathrm{Li}$ Y and Wang L: Metformin inhibits proliferation and enhances chemosensitivity of intrahepatic cholangiocarcinoma cell lines. Oncol Rep 31: 2611-2618, 2014.

39. Kastan MB and Bartek J: Cell-cycle checkpoints and cancer. Nature 432: 316-323, 2004.

40. Brooks $\mathrm{G}$ and La Thangue NB: The cell cycle and drug discovery: The promise and the hope. Drug Discov Today 4: 455-464, 1999.

41. Chiruvella KK and Raghavan SC: A natural compound, methyl angolensate, induces mitochondrial pathway of apoptosis in Daudi cells. Invest New Drugs 29: 583-592, 2011.

42. Sung WK, Zheng H, Li S, Chen R, Liu X, Li Y, Lee NP, Lee WH, Ariyaratne PN, Tennakoon C, et al: Genome-wide survey of recurrent $\mathrm{HBV}$ integration in hepatocellular carcinoma. Nat Genet 44: 765-769, 2012.

43. Taylor WR and Stark GR: Regulation of the G2/M transition by p53. Oncogene 20: 1803-1815, 2001.

44. Li J, Cheung HY, Zhang Z, Chan GK and Fong W: Andrographolide induces cell cycle arrest at G2/M phase and cell death in HepG2 cells via alteration of reactive oxygen species. Eur J Pharmacol 568: 31-44, 2007. 
45. Hadfield JA, Ducki S, Hirst N and McGown AT: Tubulin and microtubules as targets for anticancer drugs. Prog Cell Cycle Res 5: 309-325, 2003

46. Kasibhatla S and Tseng B: Why target apoptosis in cancer treatment? Mol Cancer Ther 2: 573-580, 2003.

47. Hanahan D and Weinberg RA: Hallmarks of cancer: The next generation. Cell 144: 646-674, 2011

48. Locatelli SL, Giacomini A, Guidetti A, Cleris L, Mortarini R, Anichini A, Gianni AM and Carlo-Stella C: Perifosine and sorafenib combination induces mitochondrial cell death and antitumor effects in NOD/SCID mice with Hodgkin lymphoma cell line xenografts. Leukemia 27: 1677-1687, 2013.

49. Dai W, Wang F, Lu J, Xia Y, He L, Chen K, Li J, Li S, Liu T, Zheng Y, et al: By reducing hexokinase 2, resveratrol induces apoptosis in HCC cells addicted to aerobic glycolysis and inhibits tumor growth in mice. Oncotarget 6: 13703-13717, 2015.

50. Yuen JS, Sim MY, Sim HG, Chong TW, Lau WK, Cheng CW and Huynh $\mathrm{H}$ : Inhibition of angiogenic and non-angiogenic targets by sorafenib in renal cell carcinoma (RCC) in a RCC xenograft model. Br J Cancer 104: 941-947, 2011.

51. Tomizawa M, Shinozaki F, Sugiyama T, Yamamoto S, Sueishi M and Yoshida T: Sorafenib suppresses the cell cycle and induces the apoptosis of hepatocellular carcinoma cell lines in serum-free media. Exp Ther Med 1: 863-866, 2010.

52. Kim YB, Jeung HC, Jeong I, Lee K, Rha SY, Chung HC and Kim GE: Mechanism of enhancement of radiation-induced cytotoxicity by sorafenib in colorectal cancer. J Radiat Res 54: 52-60, 2012.
53. Chipuk JE and Green DR: How do BCL-2 proteins induce mitochondrial outer membrane permeabilization? Trends Cell Biol 18: 157-164, 2008.

54. Ola MS, Nawaz M and Ahsan $\mathrm{H}$ : Role of Bcl-2 family proteins and caspases in the regulation of apoptosis. Mol Cell Biochem 351: $41-58,2011$.

55. Zhao X, Tian C, Puszyk WM, Ogunwobi OO, Cao M, Wang T, Cabrera R, Nelson DR and Liu C: OPA1 downregulation is involved in sorafenib-induced apoptosis in hepatocellular carcinoma. Lab Invest 93: 8-19, 2012.

56. Ramirez-Labrada A, López-Royuela N, Jarauta V, Galán-Malo P Azaceta G, Palomera L, Pardo J, Anel A, Marzo I and Naval J: Two death pathways induced by sorafenib in myeloma cells: Puma-mediated apoptosis and necroptosis. Clin Trans Oncol 17: 121-132, 2015.

57. Cervello M, Bachvarov D, Lampiasi N, Cusimano A, Azzolina A, McCubrey JA and Montalto G: Molecular mechanisms of sorafenib action in liver cancer cells. Cell Cycle 11: 2843-2855, 2012.

This work is licensed under a Creative Commons Attribution-NonCommercial-NoDerivatives 4.0 International (CC BY-NC-ND 4.0) License. 